\title{
An atypical NLR protein modulates the NRC immune receptor network
}

\author{
Hiroaki Adachi ${ }^{1,2}$, Toshiyuki Sakai ${ }^{1,3}$, Adeline Harant ${ }^{1}$, Cian Duggan ${ }^{4}$, Tolga O Bozkurt ${ }^{4}$, Chih-
} hang $\mathrm{Wu}^{1,5^{*}}$, Sophien Kamoun ${ }^{1^{*}}$

\author{
${ }^{1}$ The Sainsbury Laboratory, University of East Anglia, Norwich Research Park, NR4 7UH, Norwich, UK \\ ${ }^{2}$ Graduate School of Biological Sciences, Nara Institute of Science and Technology, Ikoma 630-0192, \\ Japan \\ ${ }^{3}$ Laboratory of Crop Evolution, Graduate School of Agriculture, Kyoto University, Mozume, Muko, \\ Kyoto 617-0001, Japan \\ ${ }^{4}$ Department of Life Sciences, Imperial College London, London, UK \\ ${ }^{5}$ Institute of Plant and Microbial Biology, Academia Sinica, Nankang, Taipei 11529, Taiwan
}

*Correspondence: wuchh@gate.sinica.edu.tw; sophien.kamoun@tsl.ac.uk

\section{ABSTRACT}

The NRC immune receptor network has evolved in asterid plants from a pair of linked genes into a genetically dispersed and phylogenetically structured network of sensor and helper NLR (nucleotide-binding domain and leucine-rich repeat-containing) proteins. In some species, such as the model plant Nicotiana benthamiana and other Solanaceae, the NRC network forms up to half of the NLRome, and NRCs are scattered throughout the genome in gene clusters of varying complexities. Here, we describe NRCX, an atypical, but essential member of the NRC family that lacks canonical features of these NLR helper proteins, such as a functional N-terminal MADA motif and the capacity to trigger autoimmunity. In contrast to other NRCs, systemic gene silencing of NRCX markedly impairs plant growth resulting in a dwarf phenotype. Remarkably, dwarfism of NRCX silenced plants is partially dependent on NRCX paralogs NRC2 and NRC3, but not NRC4. Despite its negative impact on plant growth when silenced systemically, transient RNA interference of $N R C X$ in mature $N$. benthamiana leaves doesn't result in visible cell death phenotypes. However, alteration of NRCX expression modulates the hypersensitive response mediated by NRC2 and NRC3 in a manner consistent with a negative role for NRCX in the NRC network. We conclude that NRCX is an atypical member of the NRC network that has evolved to contribute to the homeostasis of this genetically unlinked NLR network.

\section{INTRODUCTION}

Plants are invaded by a multitude of pathogens and pests, some of which threaten food security in recurrent cycles of destructive epidemics. Yet, most plants are resistant to most parasites through their highly effective immune system. Plant defense consists of an expanded and diverse repertoire of immune receptors: cell-surface pattern recognition receptors (PRRs) and intracellular nucleotide-binding domain and leucine-rich repeatcontaining (NLRs) proteins (Lu and Tsuda, 2021). Pathogen-associated molecular patterns (PAMPs) are recognized in the extracellular space by PRRs, resulting in pattern-triggered 
immunity (PTI) (Boutrot and Zipfel, 2017; DeFalco and Zipfel, 2021). NLRs perceive pathogen secreted proteins known as effectors and induce robust immune responses that generally include hypersensitive cell death (Jones et al., 2016; Kourelis and van der Hoorn, 2018; Saur et al., 2021). NLR-mediated immunity (also known as effector-triggered immunity) can be effective in restricting pathogen infection at invasion sites, and NLRs have also been recently shown to be involved in PRR-mediated signalling (Ngou et al., 2021a; Pruitt et al., 2021; Tian et al., 2021; Kourelis et al., 2021b). However, NLR-mediated immunity comes at a cost for plants. NLR mis-regulation and inappropriate activation can lead to deleterious physiological phenotypes, resulting in growth suppression and autoimmunity (Karasov et al., 2017), and the evolution of the plant immune system is constrained by fitness trade-offs between growth and immunity (Li and Weigel, 2021; Wan et al., 2021). However, our knowledge of the mechanisms by which diverse plant NLRs are regulated is still somewhat limited. Understanding how plants maintain NLR network homeostasis should help guide breeding disease resistant crops with limited fitness penalties.

NLRs occur across all kingdoms of life and generally function in innate immunity through "non-self" perception of invading pathogens (Jones et al., 2016; Uehling et al., 2017; Duxbury et al., 2021). Plant NLRs share a multidomain architecture typically consisting of a central NBARC (nucleotide-binding domain shared with APAF-1, various R-proteins and CED-4) and a Cterminal leucine-rich repeat (LRR) domain (Kourelis et al., 2021a). Plant NLRs can be sorted into sub-classes based on NB-ARC phylogenetic clustering and the type of $\mathrm{N}$-terminal domain they carry (Shao et al., 2016; Kourelis et al., 2021a). The largest class of NLRs are the CC-NLRs with the Rx-type coiled-coil (CC) domain preceding the NB-ARC domain (Tamborski and Krasileva, 2020; Kourelis et al., 2021a; Lee et al. 2021). A prototypical ancient CC-NLR is the HOPZ-ACTIVATED RESISTANCE1 (ZAR1), which has remained relatively conserved throughout evolution over tens of millions of years (Adachi et al., 2021). However, the majority of CCNLRs have massively expanded throughout their evolution, acquiring new activities through sequence diversification and integration of extraneous domains (Barragan and Weigel, 2021; Prigozhin and Krasileva, 2021), as well as losing particular molecular features following subfunctionalization (Adachi et al., 2019b).

Even though some plant NLRs function as singletons carrying both pathogen sensing and immune signalling activities, other NLRs form genetic and biochemical networks with varying degrees of complexity (Wu et al., 2018; Adachi et al., 2019a; Ngou et al., 2021b). NLRs can also cause deleterious genetic interactions known as hybrid incompatibility, presumably because mismatched NLRs inadvertently activate immunity (Li and Weigel, 2021; Wan et al., 2021). Hybrid autoimmunity is probably a trade-off of the rapidly evolving NLRome, which is expanding and diversifying in most angiosperm taxa, even at the intraspecific level (Van de Weyer et al., 2019; Lee and Chae, 2020; Prigozhin and Krasileva, 2021). NLRs can also cause a spontaneous autoimmune phenotype known as lesion mimicry (Bruggeman et al., 2015). Classic examples include mutants of the Toll/interleukin-1 receptor (TIR)-NLRs, ssi4 (suppressor of SA insensitivity 4), snc1 (suppressor of npr1-1, constitutive 1), s/h1 (sensitive to low humidity 1), chs1 (chilling-sensitive mutant 1), chs2 and chs3, which exhibit autoimmune phenotypes in Arabidopsis (Shirano et al., 2002; Zhang et al., 2003; Noutoshi et al., 2005; Huang et al., 2010; Yang et al., 2010; Bi et al., 2011; Wang et al., 2013). Other Arabidopsis NLRs, such as laz5 (lazarus 5), adr1 (activated disease resistance 1), summ2 (suppressor of mkk1 mkk2, 2), rps4 (resistance to Pseudomonas syringae 4), csa1 (constitutive shade- 
avoidance 1), soc3 (suppressor of chs1-2, 3), and sikic (sidekick snc1) are genetic suppressors of autoimmunity or cell death phenotypes (Palma et al., 2010; Bonardi et al., 2011; Zhang et al., 2012; Sohn et al., 2014; Xu et al., 2015; Zhang et al., 2017; Dong et al., 2018; Wu et al., 2020; Schulze et al., 2021). Nonetheless, to date, NLRs are not classed among so-called "lethal-phenotype genes" that are essential for plant viability and survival (Lloyd et al., 2015). This is despite the fact that $~ 500$ NLR genes have been experimentally studied (Kourelis et al., 2021a).

Our understanding of molecular mechanisms underpinning plant NLR activation and the subsequent signalling events has significantly advanced with the elucidation of NLR protein structures. Activated CC-NLR ZAR1, TIR-NLRs RECOGNITION OF XOPQ 1 (ROQ1) and RESISTANCE TO PERONOSPORA PARASITICA 1 (RPP1) oligomerize into multimeric complexes known as resistosomes (Wang et al., 2019a; 2019b; Martin et al., 2020; Ma et al., 2020). In the case of ZAR1, activation by pathogens induces a switch from ADP to dATP/ATP binding and oligomerization into a pentameric resistosome (Wang et al., 2019b). This results in a conformational 'death switch', with the five $\mathrm{N}$-terminal $\alpha 1$ helices forming a funnel-shaped structure that acts as a $\mathrm{Ca}^{2+}$ channel on the plasma membrane (Bi et al., 2021). The $\alpha 1$ helix of ZAR1 and about one-fifth of angiosperm CC-NLRs are defined by a molecular signature, the MADA motif (Adachi et al., 2019b). This $\alpha 1$ /MADA helix is interchangeable between distantly related NLRs indicating that the 'death switch' mechanism applies to MADA-CC-NLRs from diverse plant taxa (Adachi et al., 2019b).

One class of MADA-CC-NLRs are the NRCs (NLR-REQUIRED FOR CELL DEATH), that are central nodes in a large NLR immune network of asterid plants (Wu et al., 2017). NRCs function as helper NLRs (NRC-H), required for a large number of sensor NLRs (NRC-S) to induce the hypersensitive response and immunity (Wu et al., 2017). These NRC-S are encoded by classical disease resistance genes that detect pathogens as diverse as viruses, bacteria, oomycetes, nematodes and insects. NRC-H and NRC-S form phylogenetic sister clades within a wider NRC superclade that makes up to half of the NLRome in the Solanaceae. This NRC superclade emerged early in asterid evolution about 100 million years ago from an ancestral pair of genetically linked NLRs (Wu et al., 2017). However, in sharp contrast to paired NLR pairs, functionally connected NRC-H and NRC-S genes are not always clustered and can be scattered throughout the plant genomes (Wu et al., 2017). Our current model is that the NRCs and their sensor evolved from bi-functional NLRs that have sub-functionalized and specialized throughout evolution (Wu et al., 2017; Adachi et al., 2019a; Adachi et al., 2019b). In support of this model, the MADA sequence has degenerated in NRC-S in contrast to the NRC-H, which carry functional $\mathrm{N}$-terminal $\alpha 1$ helices (Adachi et al., 2019b).

Plant-pathogen coevolution has driven NLRs to form immune receptor networks (Wu et al. 2018; Ngou et al., 2021b). The emerging paradigm in the field of plant immunity is that helper NLRs, NRCs, as well as the $C_{R}-N L R s$ ADR1 and N REQUIREMENT GENE 1 (NRG1), form receptor networks with multiple sensor NLRs (Adachi et al., 2019a; Feehan et al., 2020). These genetically dispersed NLR networks are likely to cause a heightened risk of autoimmunity during plant growth and development. Yet, the regulatory mechanisms that attenuate such deleterious effects of NLR networks are unknown. Here, we describe NRCX, an atypical NLR protein that belongs to the NRC-H phylogenetic clade. Gene silencing of NRCX markedly impairs plant growth, presumably because of mis-activation of its helper NLR paralogs NRC2 
and NRC3. We propose that NRCX maintains NRC network homeostasis by modulating the activities of key helper NLR nodes during plant growth.

\section{RESULTS}

\section{Systemic silencing of NRCX impairs Nicotiana benthamiana growth}

Mis-regulated NLRs trigger physiological phenotypes in plants including a dwarfism associated with autoimmunity (Karasov et al., 2017; Li and Weigel, 2021; Wan et al., 2021). However, to date, NLRs have not been classed among the genes that are essential for plant viability (Lloyd et al., 2015). While performing virus-induced gene silencing (VIGS) of NRC family genes in the model plant Nicotiana benthamiana (SI Appendix, Fig. S1), we found that silencing of NLR NbS00030243g0001.1 (referred to from here on as NRCX) causes a severe dwarf phenotype (Fig. $1 \mathrm{~A}$ and B). In these VIGS experiments, we also independently targeted NRC helper (NRC-H) genes, NRC2, NRC3 and NRC4, as well as the NRC sensor (NRC-S) gene Prf (NRC2/3 dependent) for silencing in N. benthamiana (Lu et al., 2003; Wu et al., 2017). Yet, none of the NRC-H and NRC-S silenced $N$. benthamiana plants showed quantitative growth defects (Fig. $1 \mathrm{~A}$ and $\mathrm{B}$ ). These results suggest that $N R C X$ is unique among NLRs described to date as a "lethal-phenotype" gene according to the definition of Lloyd et al. (2015). NRCX silencing could lead to NLR mis-regulation, thereby resulting in the dwarf phenotype in $N$. benthamiana plants.

A

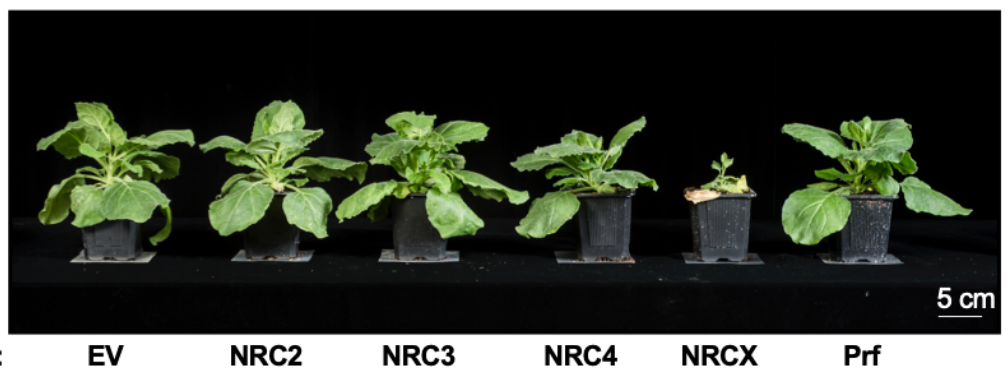

B

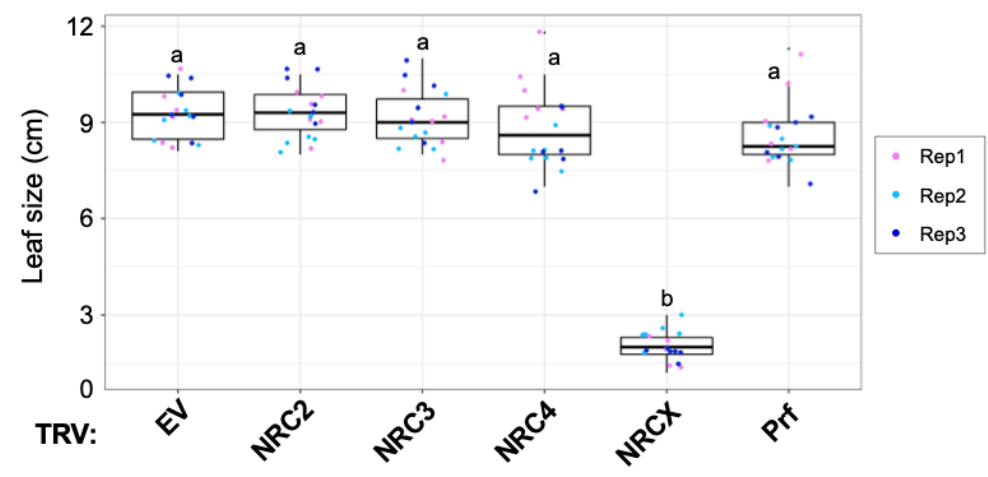

Fig. 1. Virus-induced gene silencing of $N R C X$ impairs $\boldsymbol{N}$. benthamiana growth. (A) The morphology of 6-weekold NRC2-, NRC3-, NRC4-, NRCX- or Prf-silenced N. benthamiana plants. 2-week-old N. benthamiana plants were infiltrated with Agrobacterium strains carrying tobacco rattle virus (TRV) VIGS constructs, and photographs were taken 4 weeks after the agroinfiltration. TRV empty vector (TRV:EV) was used as a negative control. (B) Quantification of the leaf size of 6-week-old NRC2-, NRC3-, NRC4-, NRCX-or Prf-silenced N. benthamiana plants. One leaf per plant was harvested from the same position (the 5th leaf from cotyledons) and was used for measuring the leaf diameter. Statistical differences among the samples were analysed with Tukey's HSD test $(p<0.01)$. 


\section{NRCX is a MADA-CC-NLR in the NRC helper phylogenetic clade}

We investigated the precise phylogenetic position of NRCX in the NRC superclade. First, we built a phylogenetic tree with 431 CC-NLRs, including the CC-NLRome from four representative plant species (Arabidopsis, sugar beet, tomato and $N$. benthamiana) and 16 representative CC-NLRs (Fig. 2A). Next, we extracted the NRC-H subclade NLRs, which includes NRCX, for further phylogenetic analysis (Fig. $2 \mathrm{~A}$ and $\mathrm{B}$ ). In this NRC-H subclade, NRCX forms a small clade together with a tomato NLR (Solyc03g005660.3.1; named as SINRCX) (Fig. 2B, SI Appendix, Fig. S2). The NRCX clade is more closely related to NRC1/2/3 subclade than to the NRC4 subclade (Fig. 2B).

We scanned NRCX and other NRC-H proteins for conserved sequence motifs (Fig. 2C). NRC-H members typically have the $\mathrm{N}$-terminal MADA motif that is functionally conserved across many dicot and monocot CC-NLRs and is required for hypersensitive cell death and disease resistance (Adachi et al., 2019b). We ran the HMMER software (Eddy, 1998) to query NRCX with a previously reported MADA motif-Hidden Markov Model (HMM) (Adachi et al., 2019b). This HMMER search detected a MADA sequence at the N-terminus of NRCX (HMM score = 22.2) and in all other NRC-H except in four N. benthamiana NRC-H proteins that have $\mathrm{N}$ terminal truncations (NbS00017924g0016.1, NbS00017801g0004.1, NbS00030989g0011.1 and NbS00020047g0002.1) (Fig. 2C). In addition, NRCX carries intact P-loop and MHD motif in its NB-ARC domain like the majority of CC-NLRs (Fig. 2C). We noted that the P-loop wasn't predicted in NbS00004191g0008.1 and NbS00004611g0006.1, and the MHD motif is absent or divergent in NbS00030989g0011.1, NbS00017801g0004.1 and Solyc04g007050.3.1 (Fig. 2C). Taken together, we conclude that NRCX has the typical sequence motifs of MADA-CCNLRs, similar to the great majority of proteins in the NRC-H subclade.

\section{The N-terminal MADA motif of NRCX is not functional and doesn't mediate hypersensitive cell death}

We investigated whether or not the MADA motif of NRCX is functional using the motif swap strategy we previously developed (Adachi et al., 2019b). To this end, we swapped the first 17 amino acids of an NRC4 autoactive MHD motif mutant (NRC4 ${ }^{\mathrm{DV}}$ ) with the equivalent region of $\mathrm{NRCX}$, resulting in a MADA ${ }^{\mathrm{NRCX}}-\mathrm{NRC} 4^{\mathrm{DV}}$ chimeric protein (Fig. $3 \mathrm{~A}-\mathrm{B}$ ). The $\mathrm{N}$-terminal sequence of NRC4 can be functionally replaced with matching sequences of other MADA-CC-NLRs, including NRC2 from $N$. benthamiana, ZAR1 from Arabidopsis and even the monocot MADA-

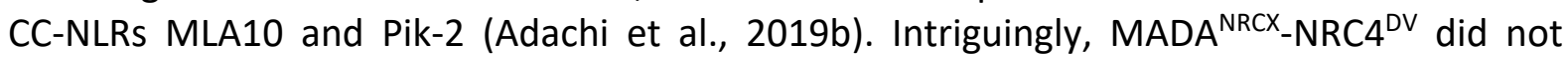
induce any visible cell death when expressed by agroinfiltration in $N$. benthamiana leaves unlike the positive controls MADA ${ }^{\text {NRC2 }}-\mathrm{NRC}^{\text {DV }}$ and MADA ${ }^{\text {ZAR1 }}{ }^{N R R C 4}{ }^{\text {DV }}$ (Fig. 3A-C). MADA ${ }^{\text {NRCX }}$ NRC4 ${ }^{\text {DV }}$ chimeric protein accumulated to similar levels as MADA ${ }^{\text {ZAR1 }}-\mathrm{NRC4}^{\text {DV }}$ in $N$. benthamiana leaves, indicating that the lack of activity was probably not due to protein destabilization (Fig. 3E). These results indicate that the MADA region of NRCX does not have the capacity to trigger hypersensitive cell death in the NRC4 protein background, and therefore despite its sequence conservation probably forms a non-functional $\mathrm{N}$-terminal $\alpha 1$ helix. 
bioRxiv preprint doi: https://doi.org/10.1101/2021.11.15.468391; this version posted November 15,2021 . The copyright holder for this preprint (which was not certified by peer review) is the author/funder, who has granted bioRxiv a license to display the preprint in perpetuity. It is made available under aCC-BY 4.0 International license.

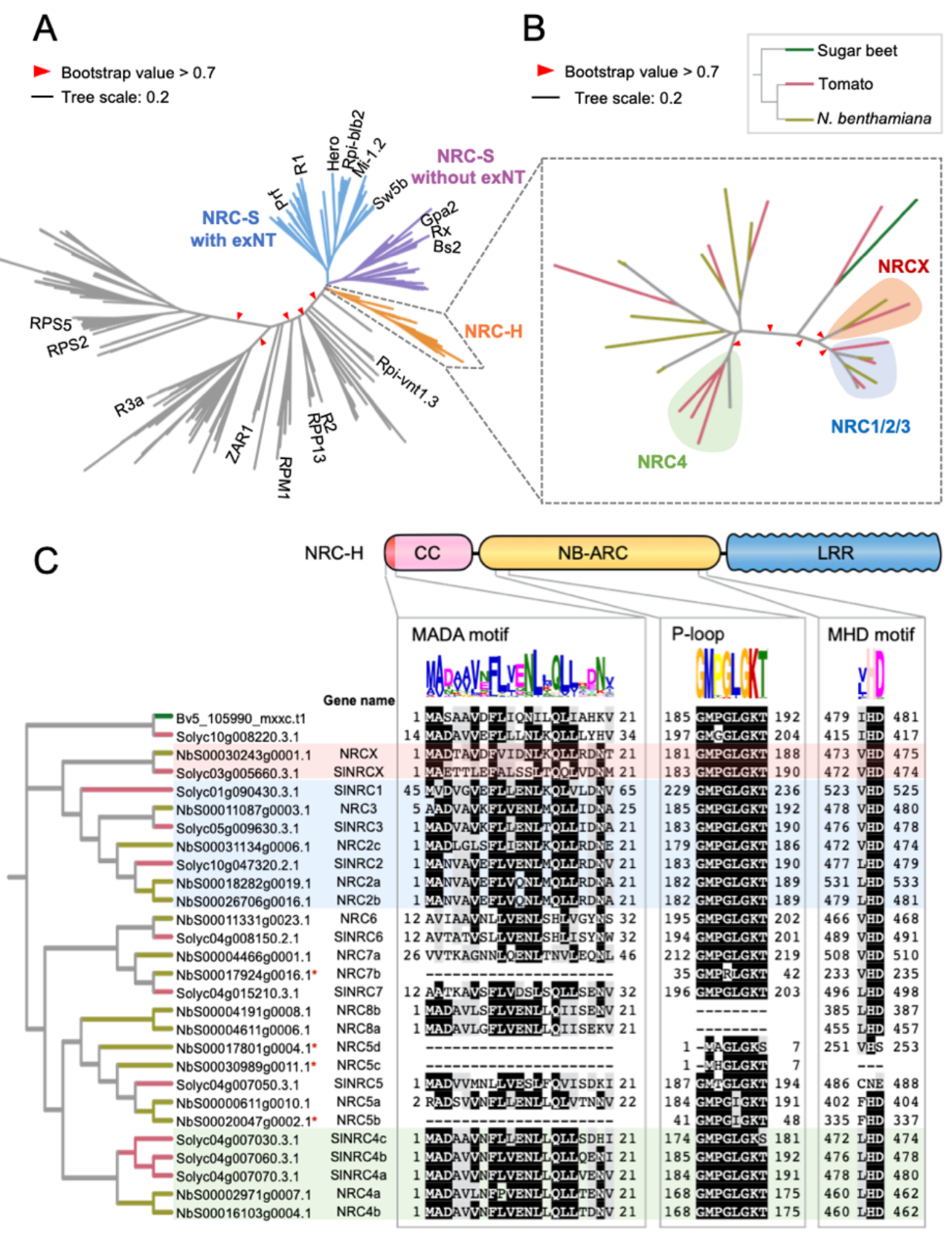

Fig. 2. NRCX is a MADA-type CC-NLR in the NRC-helper clade. (A, B) NRCX is an NRC-helper (NRC-H) member phylogenetically closely related to the NRC1/2/3 clade. The maximum likelihood phylogenetic tree was generated in RAxML version 8.2.12 with JTT model using NB-ARC domain sequences of 431 NLRs identified from N. benthamiana (NbS-), tomato (Solyc-), sugar beet (Bv-), and Arabidopsis (AT-) (SI Appendix, File S3). The NRC superclade containing NRC-H and NRC-sensor (NRC-S) clades are described with different branch colours. The NRC-S clade is divided into NLRs that lack an extended N-terminal domain (exNT) prior to their CC domain and those that carry an exNT. The NRC-H clade phylogenetic tree is shown with different colours based on plant species (B). Red arrow heads indicate bootstrap support $>0.7$ and is shown for the relevant nodes. The scale bars indicate the evolutionary distance in amino acid substitution per site. (C) Domain and motif architectures of NRC-H clade members. Amino acid sequences of MADA motif, P-loop and MHD motif are mapped onto the NRC-H phylogenetic tree. Each motif was identified in MEME using NRC-H sequences. NRCX, NRC1/2/3 and NRC4 clades are highlighted in red, blue and green, respectively. 

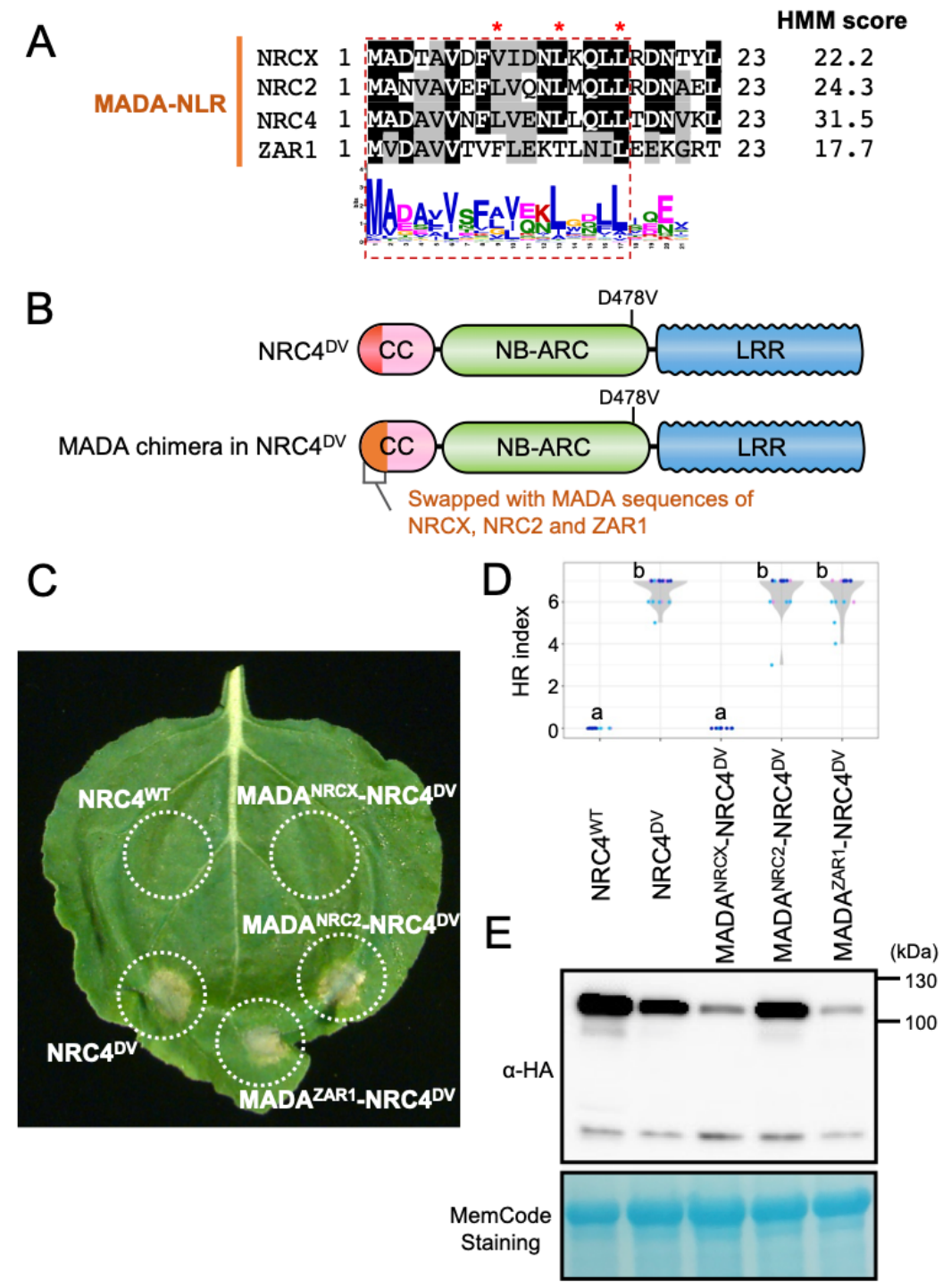

Fig. 3. Unlike other MADA-CC-NLRs, the N-terminal 17 amino acids of NRCX fails to confer cell death activity to an NRC4 autoactive mutant. (A) Alignment of the N-terminal region of the MADA-CC-NLRs, NRCX, NRC2, NRC4 and ZAR1. Key residues for cell death activity (Adachi et al. 2019b) are marked with red asterisks in the sequence alignment. Each HMM score is indicated. (B) Schematic representation of NRC4 MADA motif chimeras. The first 17 amino acid region of NRCX, NRC2 and ZAR1 was swapped into the autoactive NRC4 mutant (NRC4 ${ }^{\mathrm{DV}}$ ), resulting in the NRC4 chimeras with MADA sequences originated from other MADA-CC-NLRs. (C) Cell death phenotypes induced by the NRC4 chimeras. NRC4 ${ }^{\mathrm{WT}}-6 \mathrm{xHA}, \mathrm{NRC} 4^{\mathrm{DV}}-6 \mathrm{xHA}$ and the chimeras were expressed in $\mathrm{N}$. benthamiana leaves by agroinfiltration. Photographs were taken at 5 days after the agroinfiltration. (D) Violin plots showing cell death intensity scored as an HR index based on three independent experiments. Statistical differences among the samples were analyzed with Tukey's honest significance difference (HSD) test $(p<0.01)$. (E) In planta accumulation of the NRC4 variants. For anti-HA immunoblots of NRC4 and the mutant proteins, total proteins were prepared from $N$. benthamiana leaves at 1 day after the agroinfiltration. Equal loading was checked with Reversible Protein Stain Kit (Thermo Fisher).

\section{Unlike other NRC helpers, mutations in the MHD motif fail to confer autoactivity to NRCX}

The absence of a functional MADA/ $\alpha 1$ helix in NRCX hints at the possibility that this NLR lacks a cell death-inducing activity. To challenge this hypothesis, we performed site-directed mutagenesis of the MHD motif predicted in the NB-ARC domain of NRCX. Previously, we showed that histidine $(H)$ to arginine $(R)$ or aspartic acid $(D)$ to valine $(V)$ substitutions within 
A

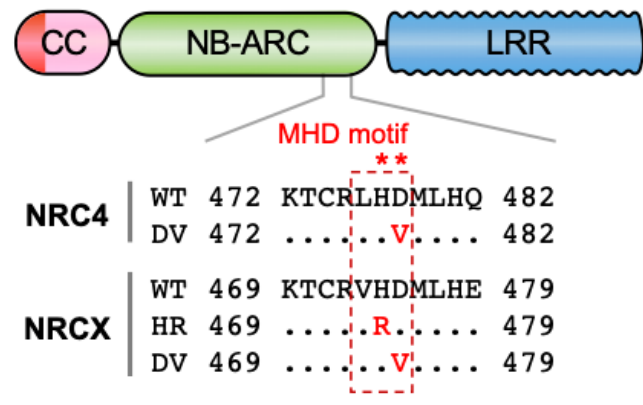

B

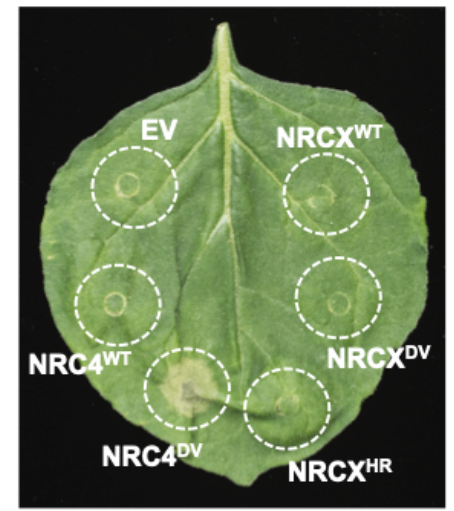

Fig. 4. Mutations in the NRCX MHD motif do not result in autoactive cell death in N. benthamiana. (A) Schematic representation of the mutated sites in the NRC4 and NRCX MHD motifs. Substituted residues are shown in red in the multiple sequence alignment. (B) NRC4 ${ }^{\mathrm{WT}}$, NRCX ${ }^{\mathrm{WT}}$ and the MHD mutants were expressed in $N$. benthamiana leaves by agroinfiltration. Cell death phenotype induced by the MHD mutant was recorded 5 days after the agroinfiltration. Quantification of the cell death intensity is shown in SI Appendix, Fig. S3.

the MHD motif confer autoactivity to the NRC helpers NRC2, NRC3 and NRC4 (Derevnina et al., 2021). Therefore, we first introduced the HR and DV mutations in NRCX (Fig. 4A). Both $N R C X^{H R}$ and $N R C X^{D V}$ did not induce macroscopic cell death when expressed in $N$. benthamiana leaves using agroinfiltration, in contrast to the autoactive NRC4 ${ }^{\mathrm{DV}}$ (Fig. 4B). To further challenge this finding, we randomly mutated NRCX $\mathrm{H} 474$ and D475 residues in the MHD motif and used agroinfiltration to express them in N. benthamiana leaves (SI Appendix, Fig. S3). None of the 55 independent NRCX MHD mutants we tested induced visible macroscopic cell death (SI Appendix, Fig. S3). These results indicate that NRCX does not have the capacity to induce cell death, unlike the other NRC-H it is related to.

\section{The dwarf phenotype of NRCX-silenced Nicotiana benthamiana plants is partially dependent on NRC2 and NRC3 but not NRC4}

We hypothesized that NRCX has a regulatory role in the NRC network, given that it belongs to the NRC helper clade but lacks the capacity to cause hypersensitive cell death. To test this hypothesis, we silenced $N R C X$ in three different $N$. benthamiana lines, $n r c 2 / 3, n r c 4$ and $n r c 2 / 3 / 4$, that we previously described as carrying loss-of-function mutations in NRC2, NRC3 and/or NRC4 (Adachi et al., 2019b; Wu et al., 2020; Witek et al., 2021) (Fig. 5). Four weeks after inoculation with TRV:NRCX, we observed partial suppression of the TRV:NRCX-mediated growth defects in $n r c 2 / 3$ and $n r c 2 / 3 / 4$ plants, but not in $n r c 4$ plants (Fig. $5 \mathrm{~A}-\mathrm{C}$ ). We confirmed that the quantitative differences were reproducible by using at least two independent lines of each of the three mutants (Fig. $5 \mathrm{~A}-\mathrm{C}$ ). In these experiments, we did not observe quantitative growth differences between $n r c 2 / 3$ and $n r c 2 / 3 / 4$ plants (Fig. $5 \mathrm{~B}$ and C).

To independently challenge these results, we performed co-silencing experiments where $N R C X$ was knocked-down together with $N R C 2 / 3, N R C 4$ or $N R C 2 / 3 / 4$. To silence multiple genes by VIGS in $N$. benthamiana plants, we tandemly cloned gene fragments of $N R C X$ and other NRCs in the same TRV expression vector. Compared to TRV:NRCX plants, the dwarf phenotype was partially suppressed in TRV:NRC2/3/X and TRV:NRC2/3/4/X, but not in TRV:NRC4/X plants (SI Appendix, Fig. S4 A-C). Each silencing construct specifically reduced mRNA levels of the 


\section{A}

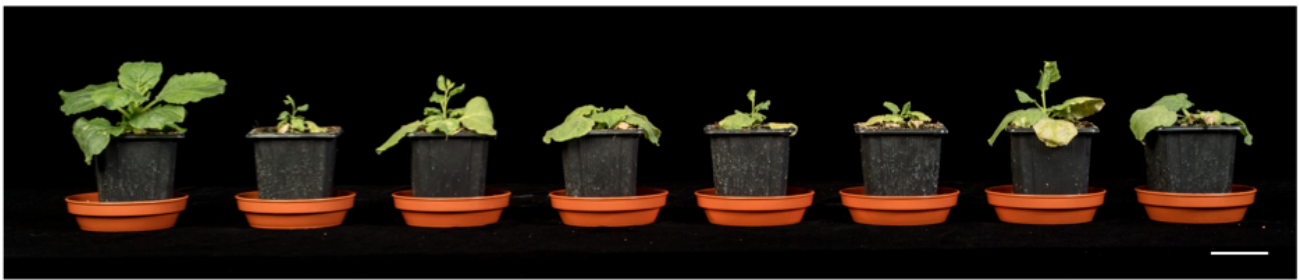

\begin{tabular}{|c|c|c|c|c|c|c|c|}
\hline Wild type & Wild type & $\begin{array}{c}n r c 2 / 3 \\
209.1 .3\end{array}$ & $\begin{array}{c}n r c 2 / 3 \\
209.3 .3\end{array}$ & $\begin{array}{c}\text { nrc4 } \\
185.1 .2\end{array}$ & $\begin{array}{c}n r c 4 \\
185.9 .1\end{array}$ & $\begin{array}{c}n r c 2 / 3 / 4 \\
210.4 .3\end{array}$ & $\begin{array}{c}n r c 2 / 3 / 4 \\
210.5 .5\end{array}$ \\
\hline
\end{tabular}

TRV:GUS

TRV:NRCX

B

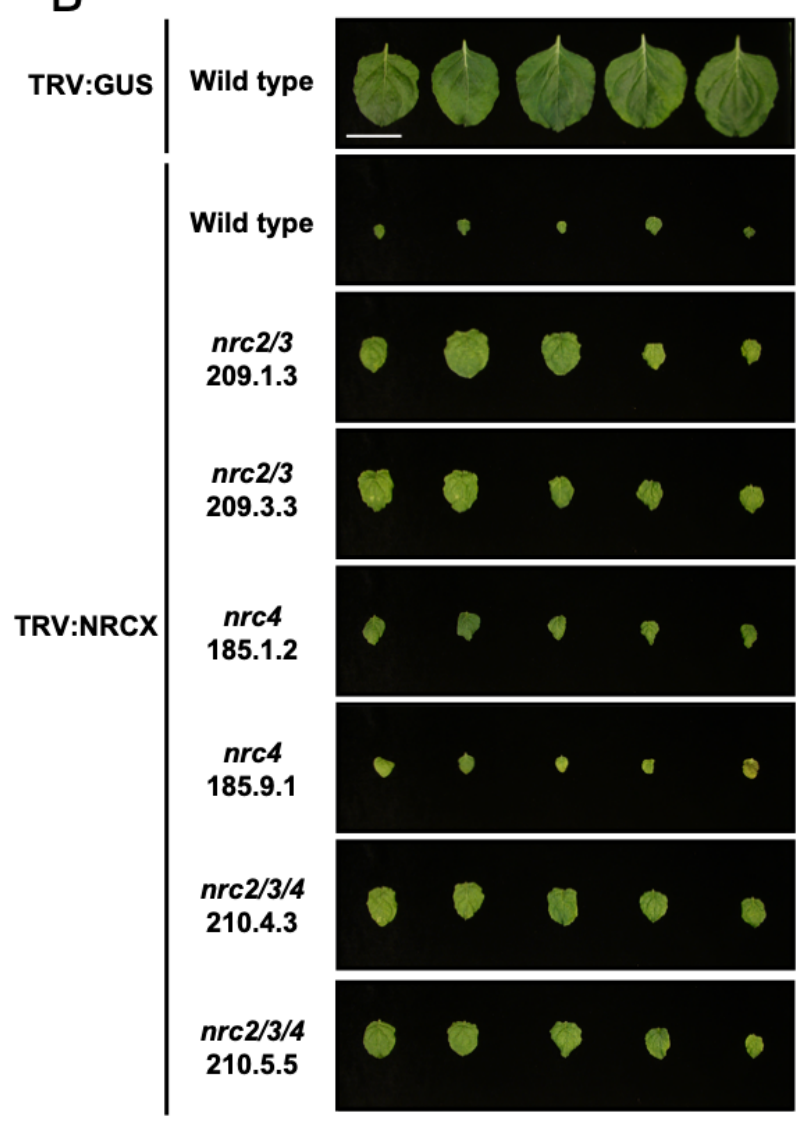

C

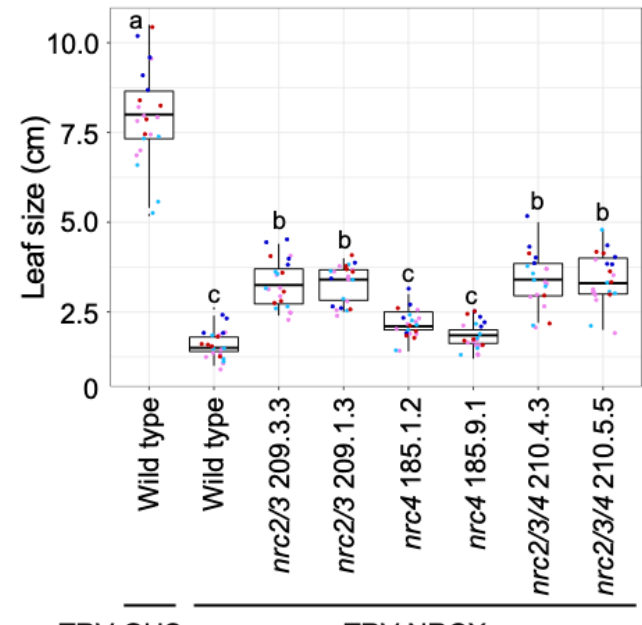

TRV:GUS

TRV:NRCX

Fig. 5. The dwarf phenotype by $N R C X$-silenced $N$. benthamiana plants is partially dependent on NRC2 and NRC3 but not NRC4. (A) The morphology of 6-week-old wild-type $N$. benthamiana, $n r c 2 / 3, n r c 4$ and $n r c 2 / 3 / 4$ CRISPR-knockout lines expressing TRV:NRCX. 2-week-old wild-type and the knockout plants were infiltrated with Agrobacterium strains carrying TRV:GUS or TRV:NRCX, and photographs were taken 4 weeks after the agroinfiltration. (B, C) Quantification of the leaf size. One leaf per each plant was harvested from the same position (the 5th leaf from cotyledons) and was used for measuring the leaf diameter. Statistical differences among the samples were analyzed with Tukey's HSD test $(p<0.01)$. Scale bars $=5 \mathrm{~cm}$.

target $N R C$ gene, indicating that phenotypic differences are unlikely to be due to off-target gene silencing effects (SI Appendix, Fig. S4D). Altogether, we conclude that the TRV:NRCXmediated dwarf phenotype is partially dependent on NRC2 and NRC3, but not NRC4.

RNA interference of NRCX in Nicotiana benthamiana leaves doesn't result in visible cell death phenotypes 
To gain further insights into NRCX activities, we generated a hairpin-silencing construct (RNAi:NRCX) for $N R C X$ silencing after transient expression in mature $N$. benthamiana leaves. First, we investigated the degree to which the RNAi:NRCX silencing construct causes cell death in $N$. benthamiana leaves, given that NLR-mediated dwarfism in plants is often linked to cell death (Zhang et al., 2012). Five days after the agroinfiltration, RNAi:NRCX did not result in macroscopic cell death in $N$. benthamiana leaves whereas co-expression of Pto/AvrPto resulted in a visible cell death response (SI Appendix, Fig. S5A). To monitor cell death at a microscopic level, we performed trypan blue staining, which generally visualizes dead cells. Trypan blue only stained trichomes in the RNAi:NRCX and RNAi:GUS (negative control) treated leaf panels, whereas it clearly revealed cell death in epidermal and mesophyll cells in the Pto/AvrPto treatment (positive control) (SI Appendix, Fig. S5 B and C). These observations indicate that RNA interference of $N R C X$ does not cause visible cell death in $N$. benthamiana leaves. This RNAi strategy also enabled us to bypass the severe dwarf phenotype observed in whole-plant VIGS experiments to perform functional analyses of NRCX.

\section{RNA interference of NRCX enhances NRC2- and NRC3-dependent cell death}

Our finding that NRC2 and NRC3 are genetic suppressors of NRCX raises the possibility that NRCX negatively modulates the activity of these helper NLRs and prompted us to investigate this hypothesis. To this end, we co-expressed by agroinfiltration in $N$. benthamiana leaves RNAi:NRCX with NRC-dependent sensor NLRs (Pto/SIPrf, Gpa2, Rpi-blb2, R1, Sw-5b and Rx) or NRC-independent NLRs (R2 and R3a) and their matching pathogen effectors (Wu et al., 2017; Derevnina et al., 2021). NRCX silencing by the hairpin construct enhanced the hypersensitive cell death triggered by the sensor NLRs SIPrf, Gpa2 (NRC2 and NRC3 dependent) and Sw-5b (NRC2, NRC3 and NRC4 dependent) relative to the RNAi:GUS control, but did not affect the other sensor NLRs, including Rpi-blb2, R1, Rx, R2 and R3a (Fig. $6 \mathrm{~A}$ and 6B and SI Appendix, Fig. S6). It should be pointed out that although NRC2, NRC3 and NRC4 redundantly contribute to effector-activated Sw-5b hypersensitive cell death (Wu et al., 2017), we recently showed that an autoactive mutant of Sw-5b (Sw-5 $b^{\text {D857V }}$ ) signals only through NRC2 and NRC3 (Derevnina et al., 2021). Therefore, we conclude that knocking-down of NRCX enhances the activities of NRC2- and NRC3-dependent NRC-S, but doesn't affect the activity of NRC-S that are only dependent on NRC4, as well as other NLR outside the NRC network.

Next, we investigated the extent to which NRCX affects the activities of autoactive mutants of the NRC-H, NRC2 ${ }^{\mathrm{H} 480 \mathrm{R}}\left(\mathrm{NRC2} 2^{\mathrm{HR}}\right.$ ), $\mathrm{NRC} 3^{\mathrm{D} 480 \mathrm{~V}}\left(\mathrm{NRC} 3^{\mathrm{DV}}\right.$ ) and $\mathrm{NRC} 4^{\mathrm{D} 478 \mathrm{~V}}\left(\mathrm{NRC} 4^{\mathrm{DV}}\right.$ ), which cause cell death even in the absence of pathogen effectors (Derevnina et al., 2021). We coexpressed NRC2 ${ }^{\mathrm{HR}}, \mathrm{NRC}^{\mathrm{DV}}$ and NRC4 ${ }^{\mathrm{DV}}$ with RNAi:NRCX or RNAi:GUS by agroinfiltration in N. benthamiana leaves. $N R C X$ silencing enhanced the cell death responses caused by $N R C 2^{\mathrm{HR}}$ and NRC $3^{\mathrm{DV}}$, but not NRC4 ${ }^{\mathrm{DV}}$, compared to the RNAi:GUS silencing control (Fig. $6 \mathrm{C}$ and D and SI Appendix, Fig. S7). RNAi:NRCX expression reduced mRNA levels of endogenous NRCX gene, but did not alter the expression of other NRCs, indicating that the enhanced cell death phenotype was probably not due to off-target silencing (Fig. 6E). Altogether, these two sets of RNAi experiments indicate that NRCX modulates the helper NLRs NRC2 and NRC3 nodes in the NRC network. 

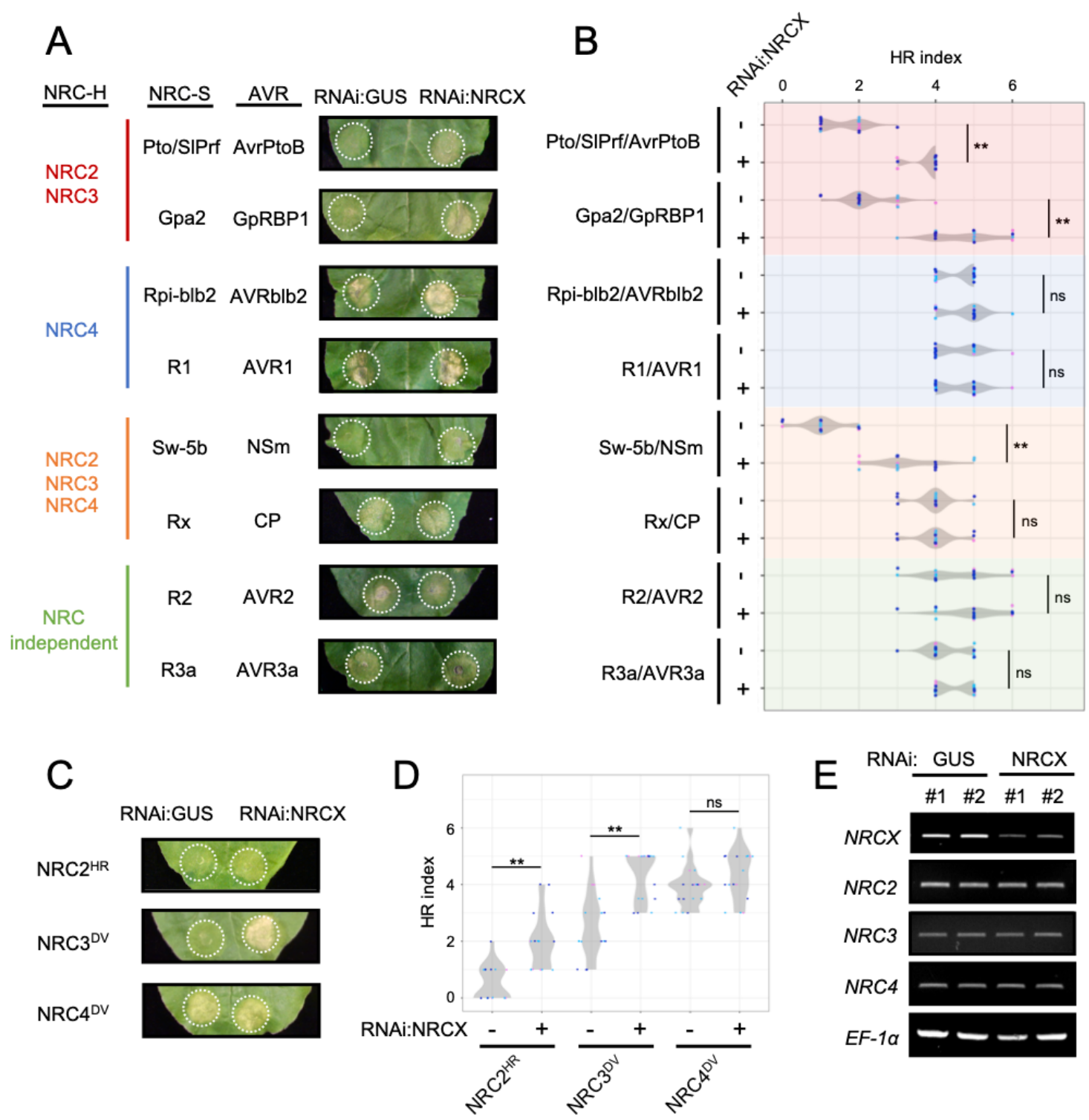

Fig. 6. RNA interference of NRCX enhances NRC2- and NRC3-dependent hypersensitive cell death. (A) Hypersensitive cell death phenotypes after co-expressing different NRC-S and AVR combinations with RNAi:GUS (control) or RNAi:NRCX by agroinfiltration. Cell death intensity was scored at 2-5 days after the agroinfiltration, and photographs were taken at 5 days after the agroinfiltration. (B) Violin plots showing cell death intensity scored as an HR index at 5 days after the agroinfiltration. Time-lapse HR index is shown in SI Appendix, Fig. S6. The HR index plots are based on three independent experiments. Asterisks indicate statistically significant differences with $t$ test $(* * p<0.01)$. (C) Autoactive cell death phenotypes induced by MHD mutants of NRC2, NRC3 and NRC4 with RNAi:GUS or RNAi:NRCX. Photos indicate cell death response at 4 days after the agroinfiltration. (D) Violin plots showing cell death intensity scored at 4 days after the agroinfiltration. Time-lapse HR index is shown in SI Appendix, Fig. S7. (E) NRCX silencing in N. benthamiana. Leaf samples were collected 2 days after agroinfiltration expressing RNAi:GUS and RNAi:NRCX. Total RNA was extracted from two independent plant samples (\#1, \#2). The expression of NRCX and other NRC-H genes were analysed in semi-quantitative RT-PCR using specific primer sets. Elongation factor $1 \alpha(E F-1 \alpha)$ was used as an internal control.

\section{NRCX overexpression compromises NRC2 and NRC3, but not NRC4, autoimmune cell death}

We further challenged our model by testing the extent to which NRCX overexpression can suppress the cell death caused by autoactive NRC2 and NRC3. We generated an overexpression construct of wild-type NRCX and co-expressed it by agroinfiltration with 
autoactive $\mathrm{NRC2} 2^{\mathrm{HR}}, \mathrm{NRC} 3^{\mathrm{DV}}$ and $\mathrm{NRC} 4^{\mathrm{DV}}$ mutants in $\mathrm{N}$. benthamiana leaves. Five days after agroinfiltration, we observed that wild-type NRCX expression compromised autoimmune cell death triggered by $\mathrm{NRC2} 2^{\mathrm{HR}}$ and $\mathrm{NRC} 3^{\mathrm{DV}}$, but not $\mathrm{NRC} 4^{\mathrm{DV}}$, relative to the empty vector control (SI Appendix, Fig. S8). Taken together, manipulation of $N R C X$ expression levels in $N$. benthamiana leaves suggests a negative role of NRCX in NRC2 and NRC3, but not NRC4, mediated immunity.

\section{$N R C X$ is differentially expressed relative to $N R C 2 a / b$ following activation of pattern- triggered immunity}

Our finding that NRCX modulates NRC2 and NRC3 nodes prompted us to investigate the transcriptome dynamics of $N R C X$ compared to these $N R C-H$ in different plant tissues. To obtain transcriptome data of NRC-H clade members, we extracted total RNA from leaf, root and flower/bud of six-week-old wild-type $N$. benthamiana. Three replicate each from independent plants were subjected to RNA-seq and resulted in 40 million 150-bp paired-end reads per sample. Then, we calculated Transcripts Per Million (TPM) values for $N$. benthamiana NLR genes (SI Appendix, Table S1). In Fig. 7a, we focused on transcriptome profiles of NRC-H with a TPM $>1.0$ and found that NRCX,NRC2a/b/c,NRC3 and NRC4a/b genes were expressed in all three tissues, leaf, root and flower/bud at relatively similar ratios. Notably, NRCX was about 3 to 5 -fold more highly expressed in roots (TPM $=25.5$ ) compared to leaves (TPM $=7.5$ ) and flowers/buds (TPM = 5.2) (Fig. 7a). In addition to the NRC2, NRC3, $N R C 4$ and $N R C X$, we also noted that $N R C 5 a$ and $N R C 8 a$ were expressed in the three tissues, whereas $N R C 7 a$ and $N R C 8 b$ were mainly expressed in $N$. benthamiana roots (Fig. 7a). These transcriptome profiles suggest that NRCX maintains NRC2/3 subnetwork homeostasis through plant growth and development in leaf, root and flower/bud.

Next, we analysed transcriptome data of six-week-old wild-type $N$. benthamiana leaves upon inoculation with avirulent bacteria Pseudomonas fluorescens (Pombo et al., 2019). P. fluorescens inoculation is considered to trigger PTI in $N$. benthamiana. We, therefore, explored the degree to which NRC-H genes are up- or down-regulated upon PTI activation. In total, 61 NLR genes were up-regulated, while 14 NLR genes were down-regulated in bacterial vs. mock treatment (Fig. 7b). Interestingly, the expression of $N R C 2 a / b$ genes was up-regulated in response to $P$. fluorescens inoculation whereas there were no particular differential expression changes with NRCX (Fig. 7b; SI Appendix, Table S2). Other NRC-H genes, such as $N R C 2 c, N R C 3$ and $N R C 4 a / b$, were also unchanged whereas the expression level of $N R C 5 a / b$ increased following bacterial treatment (Fig. 7b). We conclude that following activation of immunity in response to bacterial inoculation, $N R C 2 a / b$ become more highly expressed than their paralog and modulator NRCX thereby altering the homeostasis of the NRC network.

\section{DISCUSSION}

Co-operating plant NLRs are currently categorized into "sensor NLR" for effector recognition or "helper NLR" for immune signalling (Adachi et al., 2019a; Feehan et al., 2020). These functionally specialized NLR sensors and helpers function in pairs or networks across many species of flowering plants. In this study, we found that NRCX, a recently diverged paralog of the NRC class of helper NLRs, is essential to sustain proper plant growth and is a modulator of the genetically dispersed NRC2/3 subnetwork. We propose that NRCX has evolved to 
bioRxiv preprint doi: https://doi.org/10.1101/2021.11.15.468391; this version posted November 15, 2021. The copyright holder for this preprint (which was not certified by peer review) is the author/funder, who has granted bioRxiv a license to display the preprint in perpetuity. It is made available under aCC-BY 4.0 International license.

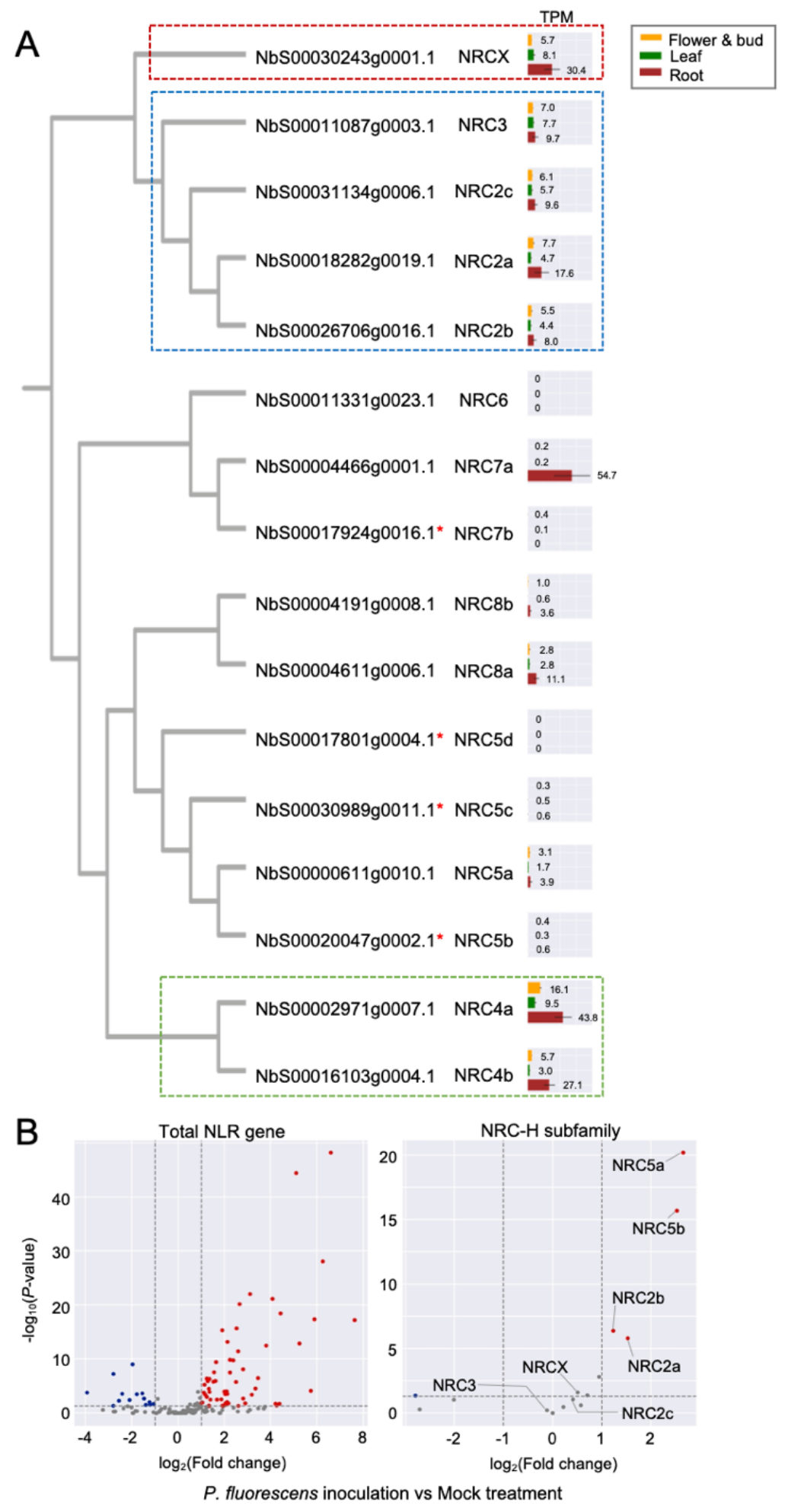

Fig. 7. NRCX is differentially expressed relative to $N R C 2 a / b$ genes in $N$. benthamiana leaves after Pseudomonas fluorescens inoculation. (A, B) TPM values were calculated using RNA-seq data of three different tissues (leaf, root, flower and bud) in 6-weeks old $N$. benthamiana plants and published transcriptome data of $N$. benthamiana leaves with mock treatment or $P$. fluorescens inoculation (Pombo et al., 2019). (A) The TPM values analysed from the three different tissue samples are mapped onto phylogeny extracted from the phylogenetic tree in Fig 2C. Red asterisks indicate truncated genes. (B) Volcano plots show up-regulated genes (red dots: $\log _{2}(P$. fluorescens/mock $) \geqq 1$ and $P$-value $\left.\leqq 0.05\right)$ and down-regulated genes (blue $\operatorname{dots} \log _{2}(P$. fluorescens/mock) $\leqq-1$ and $P$-value $\leqq 0.05)$ in response to $P$. fluorescens inoculation compared to mock treatment. 
maintain the homeostasis of at least a section of the NRC network (Fig. 8). NRCX is also atypical as far as NLR helpers and NRC proteins go, lacking a functional N-terminal MADA motif and the capacity to trigger hypersensitive cell death. At the moment, we cannot categorize NRCX as either a sensor or helper NLR, and it is best described as an NLR modulator.

NLRs are often implicated in spontaneous autoimmune phenotypes in plants and humans (Karasov et al., 2017; Feerick and McKernan, 2017). In plants, autoimmunity is often observed at the $\mathrm{F} 1$ and later generations when genetically distinct plant accessions are crossed (Karasov et al., 2017; Li and Weigel, 2021; Wan et al., 2021). One well-studied case of hybrid autoimmunity is induced by a hetero-complex of NLRs from genetically unlinked NLR gene loci between DANGEROUS MIX 1 (DM1) from Arabidopsis accession Uk-3 and DM2 from Uk1 (Bomblies et al., 2007; Chae et al., 2014; Tran et al., 2017). Therefore, hybrid incompatibility can be due to inappropriate activation of mismatched NLRs. Amino acid insertions or substitutions in NLR genes can also exhibit autoimmune phenotypes in Arabidopsis, such as in the NLR alleles ssi4 (G422R), snc1 (E552K), slh1 (single leucine insertion to RRS1 WRKY domain), chs1 (A10T), chs2 (S389F) and chs3-2D (C1340Y) (Shirano et al., 2002; Zhang et al., 2003; Noutoshi et al., 2005; Huang et al., 2010; Bi et al., 2011; Wang et al., 2013). In chs3-1, a truncation of the C-terminal LIM-containing domain causes autoimmunity (Yang et al., 2010). However, to date, T-DNA insertion or deletion mutants including chs3-2, where expression of full-length NLR modules is suppressed, do not show autoimmune phenotypes (Zhang et al., 2003; Yang et al., 2010; Narusaka et al., 2016; Zhang et al., 2017). Therefore, autoimmune $N L R$ mutants are typically considered gain-of-function mutants. A striking finding in this study is that $N R C X$ silencing resulted in severe dwarfism (Fig. 1). To our knowledge, this finding is a unique example where loss-of-function of an NLR gene causes a "lethal" plant phenotype, following the definition by Lloyd et al. (2015). Therefore, NRCX can be classified as an essential plant gene, which is exceptional given that NLR genes tend to act just the opposite way, by causing fitness penalties.

NRC2 and NRC3 partially suppress the dwarf phenotype of NRCX-silenced plants and can be viewed as genetic suppressors of NRCX (Fig. 1 and Fig. 5). These findings inspired us to draw a model which expands our understanding of the NRC network to include NRCX as a modulator of the NRC2 and NRC3 nodes (Fig. 8). This network even connects NLRs to cellsurface immune receptors, given that Kourelis et al. (2021b) recently showed that NRC3 is required for the hypersensitive cell death triggered by the receptor protein $\mathrm{Cf}-4$. We propose that NRCX contributes to the homeostasis of the NRC2/3 subnetwork, which are hubs in an immune network composed of both intracellular NRC-S and the cell-surface receptors. When the expression level of NRCX is reduced, NRC2 and NRC3 cause autoimmunity, possibly through inadvertent activation (Fig. 8). However, transient RNA interference of NRCX in N. benthamiana leaves did not cause autoimmune cell death (SI Appendix, Fig. S5), although it enhanced the hypersensitive cell death elicited by effector recognition (Fig. 6). This indicates that NRCX-mediated dwarfism is trigger-dependent and may occur in particular tissues and/or during certain developmental stages presumably in a manner similar to pathogen recognition. Considering that $n r c 2 / n r c 3$ knockout plants do not fully recover from dwarfism (Fig. 5), it is possible that NRCX silencing leads to a permanent "trigger-happy" status of $\mathrm{NRC2} / 3$ and other NLR(s) that ultimately perturbs plant growth. 


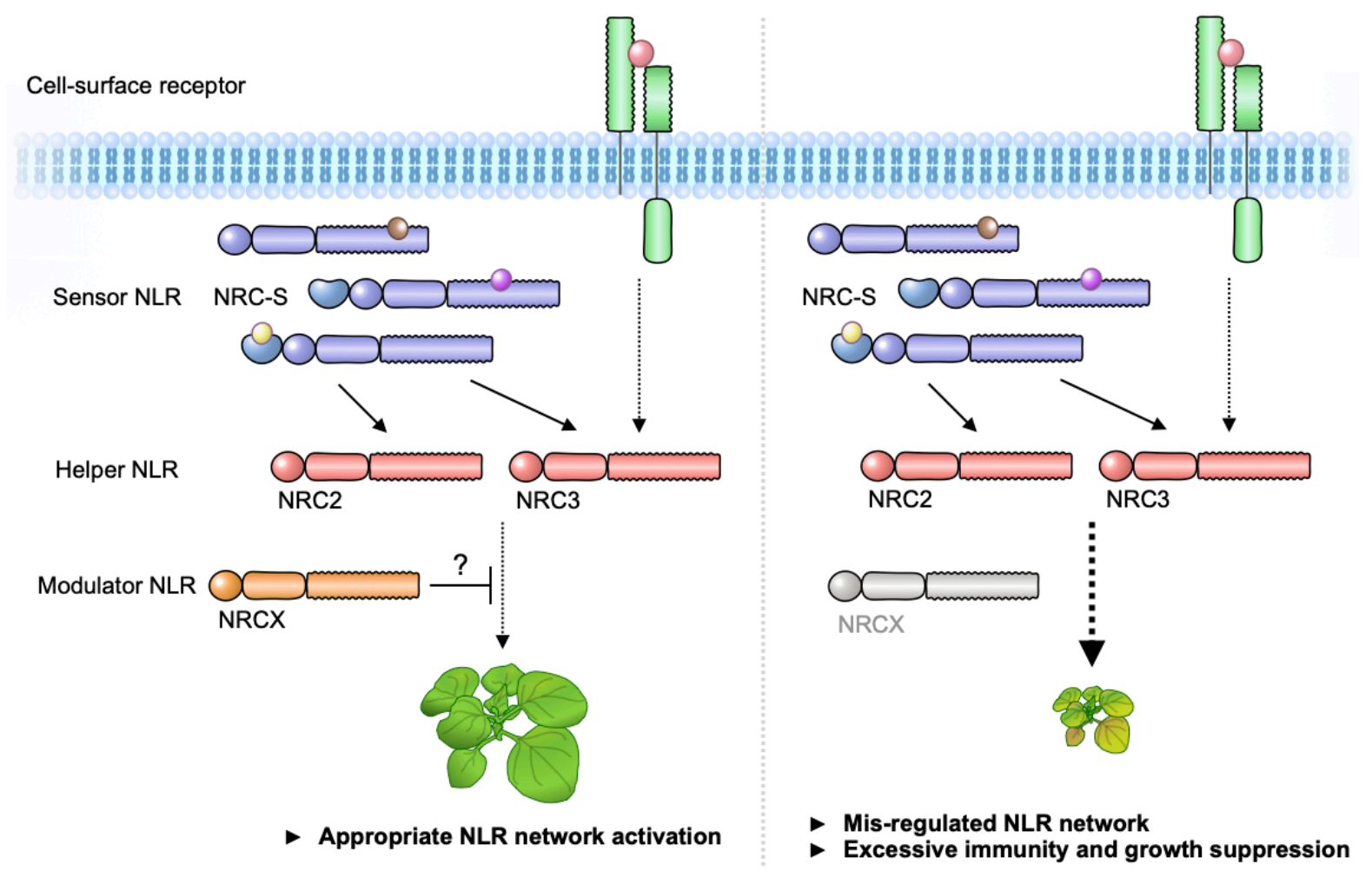

Fig. 8. Modulator NLR has evolved to maintain NLR network homeostasis. We propose that "Modulator NLR" contributes to NLR immune receptor network homeostasis during plant growth. A modulator NRCX has a similar sequence signature with helper MADA-CC-NLRs, but unlike helpers, NRCX lacks the functional MADA motif to execute cell response. NRCX modulates the NRC2/NRC3 subnetwork composed of multiple sensor NLRs and cellsurface receptor (left). Loss of function of NRCX leads to the enhanced hypersensitive response and dwarfism in N. benthamiana plants (right).

NRCX clusters within the NRC-H subclade, which is populated with proteins with a MADA-CCNLR architecture (Fig. 2). However, the N-terminal MADA motif of NRCX was not functional when swapped into NRC4 (Fig. 3), compared to other similar swaps we previously tested (Adachi et al., 2019b; Duggan et al., 2021a; Kourelis et al. 2021b). We conclude that the MADA motif of NRCX has degenerated from the canonical sequence present in the typical NRC helper NLRs and lost the capacity to execute the hypersensitive cell death response. In fact, a polymorphism in the NRCX MADA motif region, Thr-4, is unique to this protein among NRC-H (Fig. 2). Therefore, loss of cell death executor activity in NRCX might represent another path in the evolution of networked NLRs besides sensor and helper NLRs, as in the NLR functional specialization "use-it-or-lose-it" model described Adachi et al. (2019b) and Kamoun (2021). We propose that NRCX has also functionally specialized into an atypical NLR protein that operates as an NLR modulator.

NRCX overexpression compromised but did not fully suppress NRC2 and NRC3 autoactive cell death (SI Appendix, Fig. S8). Its suppressor activity contrasts with that of the SPRYSEC15 effector from the cyst nematode Globodera rostochiensis and AVRcap1b from the oomycete Phytophthora infestans, which strongly suppress the cell death inducing activity of autoimmune NRC2 and NRC3 (Derevnina et al., 2021). In the future, it will be interesting to determine the mechanism by which NRCX modulates the activities of NRC-H proteins, and how that process compares with pathogen suppression of the NRC network. 
Our work on NRCX adds to a growing body of knowledge about NLRs that modulate the activities of other NLRs. Classic examples include genetically linked NLR pairs, such as the Pia RGA5/RGA4 pair, in which the sensor RGA5 suppresses the RGA4 autoimmune cell death observed in N. benthamiana (Césari et al., 2014). In this and other one-to-one paired NLRs, the sensor NLR carries a regulatory role of its genetically linked helper mate that is released by the matching pathogen effector. In contrast, NRCX modulates a genetically dispersed NLR network composed of a large number of sensor NLRs and two helper NLRs, NRC2 and NRC3. Recently, Wu et al. (2021) showed that overexpression of NRG1C, antagonizes autoimmunity by its paralog NRG1A, chs3-2D and snc1, without affecting chs1, chs2 autoimmunity and RPS2and RPS4-mediated immunity. NRG1 is a member of $C_{R}-N L R$ helper subfamily that triggers cell death via its $\mathrm{N}$-terminal $\mathrm{CC}_{R}$ domain (Jacob et al., 2021). Intriguingly, unlike NRCX, NRG1C has a truncated NLR architecture, lacking the whole $\mathrm{N}$-terminal $\mathrm{CC}_{R}$ domain and is therefore unlikely to execute the hypersensitive cell death (Wu et al., 2021). The emerging picture is that NRCX and NRG1C are an atypical subclass of helper NLRs, we term modulator NLRs, that lost their cell death executor activity through regressive evolution and evolved to modulate the activities of multiple NLR helper proteins. These examples form another case of functional specialization during the transitions associated with NLR evolution (Kamoun, 2021). We need a better appreciation of the diversity of structures and functions that come with the protein we classify as NLR immune receptors and integrate the different ways NLRs contribute to immunity (Adachi et al., 2019a; Feehan et al., 2020; Kourelis et al. 2021a; Kamoun, 2021).

Plant NLRs are tightly regulated at the transcript level because increased expression of NLRs can result in autoimmune phenotypes and fitness costs (Li et al., 2007; Gloggnitzer et al., 2014; Tsuchiya and Eulgem, 2013; Lai et al., 2020). However, activation of plant defense is associated with massive up-regulation of NLR genes. For instance, in Arabidopsis, dozens of $N L R$ genes are up-regulated in response to pathogen-related treatments, such as the bacterial PAMP flg22 (Mohr et al., 2010; Yu et al., 2013). The current model is that NLR expression level is maintained at a low basal level but is amplified in the cells upon activation of pathogeninduced immunity. In our analyses, we found that $61 N L R$ genes, including $N R C 2 a / b$, are upregulated in $N$. benthamiana leaves following $P$. fluorescens inoculation, while $N R C X$ expression levels remain unchanged (Fig. 7b). This marked shift in the balance between $N R C 2 a / b$ to $N R C X$ expression levels may potentiate and amplify the activity of the NRC network resulting in more robust immune responses (Fig. 8).

The NRC superclade forms a large and complex NLR immune receptor network in asterid plants that connects to cell surface receptors (Wu et al., 2017; Kourelis et al. 2021b). Here we show that NRCX modulates the hub NLR proteins NRC2 and NRC3, but doesn't affect their paralog NRC4. Further studies are required to determine the molecular mechanisms underpinning NRCX antagonism of NRC2- and NRC3-mediated immune response and what other mechanisms modulate other sections of the network, such as the NRC4 subnetwork. Our findings also highlight the potential fitness costs associated with expanded NLR networks as the risk of inadvertent activation increases with the network complexity. Indeed, we found that NRCX regulation of NRC2 and NRC3 is essential for normal plant growth and development. Further understanding of how NLR network homeostasis is maintained will provide insights for future breeding of vigorous and disease resistant crops. 


\section{MATERIALS AND METHODS}

\section{Plant growth conditions}

Wild-type and mutant Nicotiana benthamiana were propagated in a glasshouse and, for most experiments, were grown in a controlled growth chamber with temperature $22-25^{\circ} \mathrm{C}$, humidity $45-65 \%$ and $16 / 8 \mathrm{hr}$ light/dark cycle. The NRC knockout lines used have been previously described: $n r c 2 / 3-209.1 .3$ and $n r c 2 / 3-209.3 .3$ (Witek et al., 2021), $n r c 4-185.1 .2$ and $n r c 4-185.9 .1$ (Adachi, et al., 2019b), and $n r c 2 / 3 / 4-210.4 .3$ and $n r c 2 / 3 / 4-210.5 .5$ (Wu et al., 2020).

\section{Plasmid constructions}

The cDNA of NRCX was amplified by PCR from $N$. benthamiana CDNA using Phusion HighFidelity DNA Polymerase (Thermo Fisher) and primers listed in SI Appendix, Table S3. The PCR product was cloned into pICSL01005 (Level 0 acceptor for CDS no stop modules, Addgene no.47996) as a level 0 module for Golden Gate assembly. To generate NRCX-3xFLAG overexpression construct, the pICSL01005::NRCX without its stop codon was used for Golden Gate assembly with pICH51266 [35S promoter $\Omega$ promoter, Addgene no. 50267], pICSL50007 (3xFLAG, Addgene no. 50308) and pICH41432 (octopine synthase terminator, Addgene no. 50343 ) into binary vector plCH47732 (Addgene no. 48000).

To generate virus-induced gene silencing constructs, the silencing fragment was amplified from template cDNA of NRCX or Prf or TRV:NRC2/3, TRV:NRC4, TRV:NRC2/3/4 plasmid (Wu et al., 2016; Wu et al., 2017) by Phusion High-Fidelity DNA Polymerase (Thermo Fisher) using primers listed in SI Appendix, Table S3. The purified amplicons were directly used in Golden Gate assembly with pTRV-GG vector according to Duggan et al. (2021b).

To generate NRCX MADA motif chimera of NRC4 (MADA ${ }^{N R C X}-N R C 4{ }^{\text {DV }}$ ), we followed a construction procedure of MADA ${ }^{\mathrm{NRC2}}-\mathrm{NRC} 4^{\mathrm{DV}}$ and MADA ${ }^{\mathrm{ZAR} 1}-\mathrm{NRC4}^{\mathrm{DV}}$ as described previously (Adachi et al., 2019b). The full-length sequence of $N R C 4^{D V}$ was amplified by Phusion HighFidelity DNA Polymerase (Thermo Fisher) using primers listed in SI Appendix, Table S3. Purified amplicons were cloned into $\mathrm{pCR} 8 / \mathrm{GW} / \mathrm{D}-\mathrm{TOPO}$ (Invitrogen) as a level 0 module. The level 0 plasmid was then used for Golden Gate assembly with pICH85281 [mannopine synthase promoter $\Omega$ (Mas $\Omega$ pro), Addgene no. 50272], pICSL50009 (6xHA, Addgene no. 50309) and pICSL60008 [Arabidopsis heat shock protein terminator (HSPter), TSL SynBio] into the binary vector plCH47742 (Addgene no. 48001).

To generate MHD mutants of NRCX, the histidine $(H)$ and aspartic acid (D) residues in the MHD motif were substituted by overlap extension PCR using Phusion High-Fidelity DNA Polymerase (Thermo Fisher). The PCR8::NRCX without its stop codon was used as a template. The mutagenesis primers are listed in SI Appendix, Table S3. The mutated NRCX was verified by DNA sequencing of the obtained plasmids.

To generate the RNAi construct, the silencing fragment was amplified from NRCX CDNA by Phusion High-Fidelity DNA Polymerase (Thermo Fisher Scientific) using primers listed in SI 
Appendix, Table S3. The purified amplicon was cloned into the pRNAi-GG vector (Yan et al., 2012).

Information of other constructs used for the cell death assays were described in SI Appendix, Table S4.

\section{Virus-induced gene silencing (VIGS)}

VIGS was performed in $N$. benthamiana as previously described (Ratcliff et al., 2001). Suspensions of Agrobacterium Gv3101 strains carrying TRV RNA1 and TRV RNA2 were mixed in a 1:1 ratio in infiltration buffer (10 $\mathrm{mM}$ 2-[N-morpholine]-ethanesulfonic acid [MES]; 10 $\mathrm{mM} \mathrm{MgCl} 2$; and $150 \mu \mathrm{M}$ acetosyringone, $\mathrm{pH}$ 5.6) to a final $\mathrm{OD}_{600}$ of 0.25 . Two-week-old $N$. benthamiana plants were infiltrated with the Agrobacterium suspensions for VIGS.

\section{Bioinformatic and phylogenetic analyses}

Based on the NLR annotation and phylogenetic tree previously described in Harant et al. (2021), we extracted CC-NLR sequences of tomato, $N$. benthamiana, $A$. thaliana and sugar beet (Beta vulgaris ssp. vulgaris var. altissima). We then added NbS00004191g0008.1 and NbS00004611g0006.1, that lack the p-loop motif in the NB-ARC domain and are therefore missing in the previous CC-NLR list (Harant et al. 2021), and prepared a CC-NLR dataset (431 protein sequences, Datasets, File S1). Amino acid sequences of the CC-NLR dataset were aligned using MAFFT v.7 (Katoh and Standley, 2013). The gaps in the alignments were deleted manually and the NB-ARC domain sequences were used for generating phylogenetic tree (Datasets, File S2). The maximum likelihood tree based on the JTT model was made in RAxML version 8.2.12 (Stamatikis, 2014) and bootstrap values based on 100 iterations were shown in Datasets, File S3.

NRC-helper proteins were subjected to motif searches using MEME (Multiple EM for Motif Elicitation) v. 5.0 .5 (Bailey and Elkan, 1994) with parameters 'zero or one occurrence per sequence, top twenty motifs', to detect consensus motifs conserved in $>80 \%$ of input sequences.

\section{Transient gene expression and cell death assays}

Transient gene expression in $N$. benthamiana was performed by agroinfiltration according to methods described by Bos et al. (2006). Briefly, four-week-old $N$. benthamiana plants were infiltrated with Agrobacterium Gv3101 strains carrying the binary expression plasmids. The Agrobacterium suspensions were prepared in infiltration buffer $(10 \mathrm{mM} \mathrm{MES}, 10 \mathrm{mM} \mathrm{MgCl}$, and $150 \mu \mathrm{M}$ acetosyringone, $\mathrm{pH}$ 5.6). To overexpress NRC MADA chimeras and MHD mutants, the concentration of each suspension was adjusted to $\mathrm{OD}_{600}=0.5$. To perform RNAi experiments in $N$. benthamiana leaves, we infiltrated Agrobacterium strains carrying RNAi constructs $\left(\mathrm{OD}_{600}=0.5\right)$, together with different proteins described in SI Appendix, Table S4. Macroscopic cell death phenotypes were scored according to the scale of Segretin et al. (2014) modified to range from 0 (no visible necrosis) to 7 (fully confluent necrosis). 
To stain dead cells by trypan blue, $N$. benthamiana leaves were transferred to a trypan blue solution (10 mL of lactic acid, $10 \mathrm{~mL}$ of glycerol, $10 \mathrm{~g}$ of phenol, $10 \mathrm{~mL}$ of water, and $10 \mathrm{mg}$ of trypan blue) diluted in ethanol $1: 1$ and were incubated at $65^{\circ} \mathrm{C}$ using a water bath for 1 hour. The leaves were then destained for 48 hours in a chloral hydrate solution (100 $\mathrm{g}$ of chloral hydrate, $5 \mathrm{~mL}$ of glycerol, and $30 \mathrm{~mL}$ of water).

\section{Protein immunoblotting}

Protein samples were prepared from six discs ( $8 \mathrm{~mm}$ diameter) cut out of $N$. benthamiana leaves at 2 days after agroinfiltration and were homogenised in extraction buffer $[10 \%(\mathrm{v} / \mathrm{v})$ glycerol, 25 mM Tris- $\mathrm{HCl}$, pH 7.5, 1 mM EDTA, $150 \mathrm{mM} \mathrm{NaCl}$, 2\% (w/v) PVPP, $10 \mathrm{mM} \mathrm{DTT,} \mathrm{1x}$ protease inhibitor cocktail (SIGMA), 0.5\% (v/v) IGEPAL (SIGMA)]. The supernatant obtained after centrifugation at $12,000 \mathrm{xg}$ for $10 \mathrm{~min}$ was used for SDS-PAGE. Immunoblotting was performed with HA-probe (F-7) HRP (Santa Cruz Biotech) in a 1:5,000 dilution. Equal loading was checked by taking images of the stained PVDF membranes with Pierce Reversible Protein Stain Kit (\#24585, Thermo Fisher Scientific).

\section{RNA extraction and semi-quantitative RT-PCR}

Total RNA was extracted using RNeasy Mini Kit (Qiagen). 500 ng RNA of each sample was subjected to reverse transcription using SuperScript ${ }^{\circledR}$ IV Reverse Transcriptase (Thermo Fisher Scientific). Semi-quantitative reverse transcription PCR (RT-PCR) was performed using DreamTaq (Thermo Fisher Scientific) with 25 to 30 amplification cycles followed by electrophoresis with $1.8 \%(\mathrm{w} / \mathrm{v})$ agarose gel stained with Ethidium bromide. Primers used for RT-PCR are listed in SI Appendix, Table S3.

\section{RNA-seq analysis}

Total RNAs of leaf, root and flower/bud tissue samples were extracted from six-week-old $N$. benthamiana plants using RNeasy Mini Kit (Qiagen). Three replicate each of the samples was sent for Illumina NovaSeq 6000 (40 M paired-end reads per sample, Novogene). Obtained RNA-seq reads were used to analyse expression profiles of NRC-helper genes in $N$. benthamiana. Reads were filtered and trimmed using FaQCs (Lo and Chain, 2014). The quality-trimmed reads were mapped to the reference $N$. benthamiana genome (Sol Genomics Network, v0.4.4) using HISAT2 (Kim et al., 2019). The number of read alignments in the gene regions were counted using featureCounts (Liao et al., 2014) and read counts were transformed into a Transcripts Per Million (TPM) value. Public RNA-seq reads from six-weekold $N$. bethamiana leaves with or without Pseudomonas fluorescens inoculation (Pombo et al., 2019), were also analysed as described above (Accession Numbers: SRP118889).

\section{Accession numbers}

NRC sequences used in this study can be found in the GenBank/EMBL and Solanaceae Genomics Network (SGN) databases with the following accession numbers: NbNRC2 (NbS00018282g0019.1 and NbS00026706g0016.1), NbNRC3 (MK692736.1), NbNRC4 (MK692737) and NbNRCX (NbS00030243g0001.1). 


\section{ACKNOWLEDGMENTS}

We are thankful to Jiorgos Kourelis, Lida Derevnina and colleagues for valuable discussions and ideas. We thank Mark Youles of TSL SynBio for invaluable technical support. This work was funded by the Gatsby Charitable Foundation and Biotechnology and Biological Sciences Research Council (BBSRC, UK). S.K. also receives funding from the European Research Council (ERC BLASTOFF projects). H.A. was funded by the Japan Society for the Promotion of Science (JSPS).

\section{COMPETING INTERESTS}

S.K. receive funding from industry on NLR biology.

\section{AUTHOR CONTRIBUTIONS}

Conceptualization: H.A., C.H.W., S.K.; Data curation: H.A., T.S., C.H.W.; Formal analysis: H.A., T.S.; Investigation: H.A., T.S., C.H.W.; Methodology: H.A., T.S., C.H.W.; Resources: H.A., T.S., A.H., C.D., T.O.B., C.H.W.; Supervision: H.A., C.H.W, S.K.; Funding acquisition: H.A., S.K.; Project administration: S.K.; Writing initial draft: H.A., S.K.; Editing: H.A., T.S., C.D., T.O.B., C.H.W., S.K.

\section{References}

Adachi H, Derevnina L, Kamoun S. NLR singletons, pairs, and networks: evolution, assembly, and regulation of the intracellular immunoreceptor circuitry of plants. Curr Opin Plant Biol. 2019a; 50:121-131. doi: 10.1016/j.pbi.2019.04.007. PMID: 31154077

Adachi H, Contreras MP, Harant A, Wu CH, Derevnina L, Sakai T, Duggan C, Moratto E, Bozkurt TO, Maqbool A, Win J, Kamoun $\mathrm{S}$. An N-terminal motif in NLR immune receptors is functionally conserved across distantly related plant species. Elife. 2019b; 8:e49956. doi: 10.7554/eLife.49956. PMID: 31774397

Adachi H, Sakai T, Kourelis J, Gonzalez Hernandez JL, Maqbool A, Kamoun S. Jurassic NLR: conserved and dynamic evolutionary features of the atypically ancient immune receptor ZAR1. bioRxiv. 2021; doi: https://doi.org/10.1101/2020.10.12.333484.

Bailey TL, Elkan C. Fitting a mixture model by expectation maximization to discover motifs in biopolymers. Proc Int Conf Intell Syst Mol Biol. 1994; 2:28-36. PMID: 7584402

Ballvora A, Ercolano MR, Weiss J, Meksem K, Bormann CA, Oberhagemann P, Salamini F, Gebhardt C. The R1 gene for potato resistance to late blight (Phytophthora infestans) belongs to the leucine zipper/NBS/LRR class of plant resistance genes. Plant J. 2002; 30:361-371. doi: 10.1046/j.1365-313x.2001.01292.x. PMID: 12000683

Barragan AC, Weigel D. Plant NLR diversity: the known unknowns of pan-NLRomes. Plant Cell. 2021; 33:814-831. doi: 10.1093/plcell/koaa002. PMID: 33793812

Bi D, Johnson KC, Zhu Z, Huang Y, Chen F, Zhang Y, Li X. Mutations in an Atypical TIR-NB-LRR-LIM Resistance Protein Confer Autoimmunity. Front Plant Sci. 2011; 2:71. doi: 10.3389/fpls.2011.00071. PMID: 22639607

Bi G, Su M, Li N, Liang Y, Dang S, Xu J, Hu M, Wang J, Zou M, Deng Y, Li Q, Huang S, Li J, Chai J, He K, Chen YH, Zhou JM. The ZAR1 resistosome is a calcium-permeable channel triggering plant immune signaling. Cell. 2021; 184:3528-3541.e12. doi: 10.1016/j.cell.2021.05.003. PMID: 33984278

Bomblies K, Lempe J, Epple P, Warthmann N, Lanz C, Dangl JL, Weigel D. Autoimmune response as a mechanism for a Dobzhansky-Muller-type incompatibility syndrome in plants. PLoS Biol. 2007; 5:e236. doi: 10.1371/journal.pbio.0050236. PMID: 17803357

Bonardi V, Tang S, Stallmann A, Roberts M, Cherkis K, Dangl JL. Expanded functions for a family of plant intracellular immune receptors beyond specific recognition of pathogen effectors. Proc Natl Acad Sci U S A. 2011; 108:16463-16468. doi: 10.1073/pnas.1113726108. PMID: 21911370

Boutrot F, Zipfel C. Function, discovery, and exploitation of plant pattern recognition receptors for broad-spectrum disease resistance. Annu Rev Phytopathol. 2017; 55:257-286. doi: 10.1146/annurev-phyto-080614-120106. PMID: 28617654

Bos JI, Kanneganti TD, Young C, Cakir C, Huitema E, Win J, Armstrong MR, Birch PR, Kamoun S. The C-terminal half of Phytophthora infestans RXLR effector AVR3a is sufficient to trigger R3a-mediated hypersensitivity and suppress INF1- 
bioRxiv preprint doi: https://doi.org/10.1101/2021.11.15.468391; this version posted November 15, 2021. The copyright holder for this preprint (which was not certified by peer review) is the author/funder, who has granted bioRxiv a license to display the preprint in perpetuity. It is made available under aCC-BY 4.0 International license.

induced cell death in Nicotiana benthamiana. Plant J. 2006; 48:165-176. doi: 10.1111/j.1365-313X.2006.02866.x. PMID: 16965554

Bozkurt TO, Schornack S, Win J, Shindo T, llyas M, Oliva R, Cano LM, Jones AM, Huitema E, van der Hoorn RA, Kamoun S. Phytophthora infestans effector AVRblb2 prevents secretion of a plant immune protease at the haustorial interface. Proc Natl Acad Sci U S A. 2011; 108:20832-20837. doi: 10.1073/pnas.1112708109. PMID: 22143776

Bruggeman Q, Raynaud C, Benhamed M, Delarue M. To die or not to die? Lessons from lesion mimic mutants. Front Plant Sci. 2015; 6:24. doi: 10.3389/fpls.2015.00024. PMID: 25688254

Césari S, Kanzaki H, Fujiwara T, Bernoux M, Chalvon V, Kawano Y, Shimamoto K, Dodds P, Terauchi R, Kroj T. The NB-LRR proteins RGA4 and RGA5 interact functionally and physically to confer disease resistance. EMBO J. 2014; 33:1941-59. doi: 10.15252/embj.201487923. PMID: 25024433

Chae E, Bomblies K, Kim ST, Karelina D, Zaidem M, Ossowski S, Martín-Pizarro C, Laitinen RA, Rowan BA, Tenenboim H, Lechner S, Demar M, Habring-Müller A, Lanz C, Rätsch G, Weigel D. Species-wide genetic incompatibility analysis identifies immune genes as hot spots of deleterious epistasis. Cell. 2014; 159:1341-51. doi: 10.1016/j.cell.2014.10.049. PMID: 25467443

de Vries JS, Andriotis VM, Wu AJ, Rathjen JP. Tomato Pto encodes a functional N-myristoylation motif that is required for signal transduction in Nicotiana benthamiana. Plant J. 2006; 45:31-45. doi: 10.1111/j.1365-313X.2005.02590.x. PMID: 16367952

DeFalco TA, Zipfel C. Molecular mechanisms of early plant pattern-triggered immune signaling. Mol Cell. 2021; 81:3449-3467. doi: 10.1016/j.molcel.2021.07.029. PMID: 34403694

Derevnina L, Contreras MP, Adachi H, Upson J, Vergara Cruces A, Xie R, Skłenar J, Menke FLH, Mugford ST, MacLean D, Ma W, Hogenhout SA, Goverse A, Maqbool A, Wu CH, Kamoun S. Plant pathogens convergently evolved to counteract redundant nodes of an NLR immune receptor network. PLoS Biol. 2021; 19:e3001136. doi: 10.1371/journal.pbio.3001136. PMID: 34424903

Dong OX, Ao K, Xu F, Johnson KCM, Wu Y, Li L, Xia S, Liu Y, Huang Y, Rodriguez E, Chen X, Chen S, Zhang Y, Petersen M, Li X. Individual components of paired typical NLR immune receptors are regulated by distinct E3 ligases. Nat Plants. 2018; 4:699-710. doi: 10.1038/s41477-018-0216-8. PMID: 30082764

Du Y, Berg J, Govers F, Bouwmeester K. Immune activation mediated by the late blight resistance protein R1 requires nuclear localization of R1 and the effector AVR1. New Phytol. 2015; 207:735-747. doi: 10.1111/nph.13355. PMID: 25760731

Duggan C, Moratto E, Savage Z, Hamilton E, Adachi H, Wu CH, Leary AY, Tumtas Y, Rothery SM, Maqbool A, Nohut S, Martin TR, Kamoun S, Bozkurt TO. Dynamic localization of a helper NLR at the plant-pathogen interface underpins pathogen recognition. Proc Natl Acad Sci U S A. 2021a; 118: e2104997118. doi: 10.1073/pnas.2104997118. PMID: 34417294

Duggan C, Tumtas Y, Bozkurt TO. A golden-gate compatible TRV2 virus induced gene silencing (VIGS) vector. Zenodo. 2021b; doi: $10.5281 /$ zenodo.5666892.

Duxbury Z, Wu CH, Ding P. A comparative overview of the intracellular guardians of plants and animals: NLRs in innate immunity and beyond. Annu Rev Plant Biol. 2021; 72:155-184. doi: 10.1146/annurev-arplant-080620-104948. PMID: 33689400

Eddy SR. Profile hidden Markov models. Bioinformatics. 1998; 14:755-763. doi: 10.1093/bioinformatics/14.9.755. PMID: 9918945

Feerick CL, McKernan DP. Understanding the regulation of pattern recognition receptors in inflammatory diseases - a 'Nod' in the right direction. Immunology. 2017; 150:237-247. doi: 10.1111/imm.12677. PMID: 27706808

Feehan JM, Castel B, Bentham AR, Jones JD. Plant NLRs get by with a little help from their friends. Curr Opin Plant Biol. 2020; 56:99-108. doi: 10.1016/j.pbi.2020.04.006. PMID: 32554226

Gloggnitzer J, Akimcheva S, Srinivasan A, Kusenda B, Riehs N, Stampfl H, Bautor J, Dekrout B, Jonak C, Jiménez-Gómez JM, Parker JE, Riha K. Nonsense-mediated mRNA decay modulates immune receptor levels to regulate plant antibacterial defense. Cell Host Microbe. 2014; 16:376-390. doi: 10.1016/j.chom.2014.08.010. PMID: 25211079

Hallwass M, de Oliveira AS, de Campos Dianese E, Lohuis D, Boiteux LS, Inoue-Nagata AK, Resende RO, Kormelink R. The Tomato spotted wilt virus cell-to-cell movement protein (NSm) triggers a hypersensitive response in Sw-5-containing resistant tomato lines and in Nicotiana benthamiana transformed with the functional $S w-5 b$ resistance gene copy. Mol Plant Pathol. 2014; 15:871-880. doi: 10.1111/mpp.12144. PMID: 24720811

Harant A, Pai H, Sakai T, Kamoun S, Adachi H. A vector system for fast-forward studies of the HOPZ-ACTIVATED RESISTANCE1 (ZAR1) resistosome in the model plant Nicotiana benthamiana. Plant Physiol. 2021; 11:kiab471. doi: 10.1093/plphys/kiab471. PMID: 34633454

Huang X, Li J, Bao F, Zhang X, Yang S. A gain-of-function mutation in the Arabidopsis disease resistance gene RPP4 confers sensitivity to low temperature. Plant Physiol. 2010; 154:796-809. doi: 10.1104/pp.110.157610. PMID: 20699401

Jacob P, Kim NH, Wu F, El-Kasmi F, Chi Y, Walton WG, Furzer OJ, Lietzan AD, Sunil S, Kempthorn K, Redinbo MR, Pei ZM, Wan L, Dangl JL. Plant "helper" immune receptors are $\mathrm{Ca}^{2+}$-permeable nonselective cation channels. Science. 2021; 373: 420425. doi: 10.1126/science.abg7917. PMID: 34140391

Jones JD, Vance RE, Dangl JL. Intracellular innate immune surveillance devices in plants and animals. Science. 2016; 354:aaf6395. doi: 10.1126/science.aaf6395. PMID: 27934708

Kamoun S. NLR receptor networks: filling the gap between evolutionary and mechanistic studies. Zenodo. 2021 doi: 10.5281/zenodo.5504059.

Karasov TL, Chae E, Herman JJ, Bergelson J. Mechanisms to mitigate the trade-off between growth and defense. Plant Cell. 2017; 29:666-680. doi: 10.1105/tpc.16.00931. PMID: 28320784 
Katoh K, Standley DM. MAFFT multiple sequence alignment software version 7: improvements in performance and usability. Mol Biol Evol. 2013; 30:772-780. doi: 10.1093/molbev/mst010. PMID: 23329690

Kim D, Paggi JM, Park C, Bennett C, Salzberg SL. Graph-based genome alignment and genotyping with HISAT2 and HISATgenotype. Nat Biotechnol. 2019; 37:907-915. doi: 10.1038/s41587-019-0201-4. PMID: 31375807

Kourelis J, van der Hoorn RAL. Defended to the nines: 25 years of resistance gene cloning identifies nine mechanisms for $\mathrm{R}$ protein function. Plant Cell. 2018; 30:285-299. doi: 10.1105/tpc.17.00579. PMID: 29382771

Kourelis J, Sakai T, Adachi H, Kamoun S. RefPlantNLR is a comprehensive collection of experimentally validated plant disease resistance proteins from the NLR family. PLoS Biol. 2021a; 19:e3001124. doi: 10.1371/journal.pbio.3001124. PMID: 34669691

Kourelis J, Contreras MP, Harant A, Adachi H, Derevnina L, Wu CH, Kamoun S. The helper NLR immune protein NRC3 mediates the hypersensitive cell death caused by the cell-surface receptor Cf-4. bioRxiv. 2021b; doi: https://doi.org/10.1101/2021.09.28.461843.

Lai Y, Lu XM, Daron J, Pan S, Wang J, Wang W, Tsuchiya T, Holub E, McDowell JM, Slotkin RK, Le Roch KG, Eulgem T. The Arabidopsis PHD-finger protein EDM2 has multiple roles in balancing NLR immune receptor gene expression. PLoS Genet. 2020; 16:e1008993. doi: 10.1371/journal.pgen.1008993. PMID: 32925902

Lee RRQ, Chae E. Variation patterns of NLR clusters in Arabidopsis thaliana genomes. Plant Commun. 2020; 1:100089. doi: 10.1016/j.xplc.2020.100089. PMID: 33367252

Lee HY, Mang H, Choi E, Seo YE, Kim MS, Oh S, Kim SB, Choi D. Genome-wide functional analysis of hot pepper immune receptors reveals an autonomous NLR clade in seed plants. New Phytol. 2021; 229:532-547. doi: 10.1111/nph.16878. PMID: 32810286

Li Y, Yang S, Yang H, Hua J. The TIR-NB-LRR gene SNC1 is regulated at the transcript level by multiple factors. Mol Plant Microbe Interact. 2007; 20:1449-1456. doi: 10.1094/MPMI-20-11-1449. PMID: 17977156

Li L, Weigel D. One hundred years of hybrid necrosis: hybrid autoimmunity as a window into the mechanisms and evolution of plant-pathogen interactions. Annu Rev Phytopathol. 2021; 59:213-237. doi: 10.1146/annurev-phyto-020620-114826. PMID: 33945695

Liao Y, Smyth GK, Shi W. featureCounts: an efficient general purpose program for assigning sequence reads to genomic features. Bioinformatics. 2014; 30:923-930. doi: 10.1093/bioinformatics/btt656. PMID: 24227677.

Lloyd JP, Seddon AE, Moghe GD, Simenc MC, Shiu SH. Characteristics of plant essential genes allow for within- and betweenspecies prediction of lethal mutant phenotypes. Plant Cell. 2015; 27:2133-2147. doi: 10.1105/tpc.15.00051. PMID: 26286535

Lo CC, Chain PS. Rapid evaluation and quality control of next generation sequencing data with FaQCs. BMC Bioinformatics. 2014; 15:366. doi: 10.1186/s12859-014-0366-2. PMID: 25408143

Lokossou AA, Park TH, van Arkel G, Arens M, Ruyter-Spira C, Morales J, Whisson SC, Birch PR, Visser RG, Jacobsen E, van der Vossen EA. Exploiting knowledge of R/Avr genes to rapidly clone a new LZ-NBS-LRR family of late blight resistance genes from potato linkage group IV. Mol Plant Microbe Interact. 2009; 22:630-641. doi: 10.1094/MPMI-22-6-0630. PMID: 19445588

Lu R, Malcuit I, Moffett P, Ruiz MT, Peart J, Wu AJ, Rathjen JP, Bendahmane A, Day L, Baulcombe DC. High throughput virusinduced gene silencing implicates heat shock protein 90 in plant disease resistance. EMBO J. 2003; 22:5690-5699. doi: 10.1093/emboj/cdg546. PMID: 14592968

Lu Y, Tsuda K. Intimate association of PRR- and NLR-mediated signaling in plant immunity. Mol Plant Microbe Interact. 2021; 34:3-14. doi: 10.1094/MPMI-08-20-0239-IA. PMID: 33048599

Ma S, Lapin D, Liu L, Sun Y, Song W, Zhang X, Logemann E, Yu D, Wang J, Jirschitzka J, Han Z, Schulze-Lefert P, Parker JE, Chai J. Direct pathogen-induced assembly of an NLR immune receptor complex to form a holoenzyme. Science. 2020; 370:eabe3069. doi: 10.1126/science.abe3069. PMID: 33273071

Martin R, Qi T, Zhang H, Liu F, King M, Toth C, Nogales E, Staskawicz BJ. Structure of the activated ROQ1 resistosome directly recognizing the pathogen effector XopQ. Science. 2020; 370:eabd9993. doi: 10.1126/science.abd9993. PMID: 33273074

Mohr TJ, Mammarella ND, Hoff T, Woffenden BJ, Jelesko JG, McDowell JM. The Arabidopsis downy mildew resistance gene $R P P 8$ is induced by pathogens and salicylic acid and is regulated by W box cis elements. Mol Plant Microbe Interact. 2010; 23:1303-1315. doi: 10.1094/MPMI-01-10-0022. PMID: 20831409

Mucyn TS, Clemente A, Andriotis VM, Balmuth AL, Oldroyd GE, Staskawicz BJ, Rathjen JP. The tomato NBARC-LRR protein Prf interacts with Pto kinase in vivo to regulate specific plant immunity. Plant Cell. 2006; 18:2792-2806. doi: 10.1105/tpc.106.044016. PMID: 17028203

Narusaka M, Toyoda K, Shiraishi T, luchi S, Takano Y, Shirasu K, Narusaka Y. Leucine zipper motif in RRS1 is crucial for the regulation of Arabidopsis dual resistance protein complex RPS4/RRS1. Sci Rep. 2016; 6:18702. doi: 10.1038/srep18702. PMID: 26750751

Ngou BPM, Ahn HK, Ding P, Jones JDG. Mutual potentiation of plant immunity by cell-surface and intracellular receptors. Nature. 2021a; 592:110-115. doi: 10.1038/s41586-021-03315-7. PMID: 33692545

Ngou BPM, Jones JDG, Ding P. Plant immune networks. Trends Plant Sci. 2021b; 18:S1360-1385(21)00243-0. doi: 10.1016/j.tplants.2021.08.012. PMID: 34548213

Noutoshi Y, Ito T, Seki M, Nakashita H, Yoshida S, Marco Y, Shirasu K, Shinozaki K. A single amino acid insertion in the WRKY domain of the Arabidopsis TIR-NBS-LRR-WRKY-type disease resistance protein SLH1 (sensitive to low humidity 1) causes activation of defense responses and hypersensitive cell death. Plant J. 2005; 43:873-88. doi: 10.1111/j.1365313X.2005.02500.x. PMID: 16146526 
bioRxiv preprint doi: https://doi.org/10.1101/2021.11.15.468391; this version posted November 15, 2021. The copyright holder for this preprint (which was not certified by peer review) is the author/funder, who has granted bioRxiv a license to display the preprint in perpetuity. It is made available under aCC-BY 4.0 International license.

Palma K, Thorgrimsen S, Malinovsky FG, Fiil BK, Nielsen HB, Brodersen P, Hofius D, Petersen M, Mundy J. Autoimmunity in Arabidopsis acd11 is mediated by epigenetic regulation of an immune receptor. PLoS Pathog. 2010; 6:e1001137. doi: 10.1371/journal.ppat.1001137. PMID: 20949080

Pombo MA, Ramos RN, Zheng Y, Fei Z, Martin GB, Rosli HG. Transcriptome-based identification and validation of reference genes for plant-bacteria interaction studies using Nicotiana benthamiana. Sci Rep. 2019; 9:1632. doi: 10.1038/s41598018-38247-2. PMID: 30733563

Prigozhin DM, Krasileva KV. Analysis of intraspecies diversity reveals a subset of highly variable plant immune receptors and predicts their binding sites. Plant Cell. 2021; 33:998-1015. doi: 10.1093/plcell/koab013. PMID: 33561286

Pruitt RN, Locci F, Wanke F, Zhang L, Saile SC, Joe A, Karelina D, Hua C, Fröhlich K, Wan WL, Hu M, Rao S, Stolze SC, Harzen A, Gust AA, Harter K, Joosten MHAJ, Thomma BPHJ, Zhou JM, Dangl JL, Weigel D, Nakagami H, Oecking C, Kasmi FE, Parker JE, Nürnberger T. The EDS1-PAD4-ADR1 node mediates Arabidopsis pattern-triggered immunity. Nature. 2021; 598:495499. doi: 10.1038/s41586-021-03829-0. PMID: 34497423

Ratcliff F, Martin-Hernandez AM, Baulcombe DC. Technical Advance. Tobacco rattle virus as a vector for analysis of gene function by silencing. Plant J. 2001; 25:237-245. doi: 10.1046/j.0960-7412.2000.00942.x. PMID: 11169199

Rathjen JP, Chang JH, Staskawicz BJ, Michelmore RW. Constitutively active Pto induces a Prf-dependent hypersensitive response in the absence of avrPto. EMBO J. 1999; 18:3232-3240. doi: 10.1093/emboj/18.12.3232. PMID: 10369664

Sacco MA, Koropacka K, Grenier E, Jaubert MJ, Blanchard A, Goverse A, Smant G, Moffett P. The cyst nematode SPRYSEC protein RBP-1 elicits Gpa2- and RanGAP2-dependent plant cell death. PLoS Pathog. 2009; 5:e1000564. doi: 10.1371/journal.ppat.1000564. PMID: 19714238

Saunders DG, Breen S, Win J, Schornack S, Hein I, Bozkurt TO, Champouret N, Vleeshouwers VG, Birch PR, Gilroy EM, Kamoun S. Host protein BSL1 associates with Phytophthora infestans RXLR effector AVR2 and the Solanum demissum Immune receptor R2 to mediate disease resistance. Plant Cell. 2012; 24:3420-3434. doi: 10.1105/tpc.112.099861. PMID: 22885736

Saur IML, Panstruga R, Schulze-Lefert P. NOD-like receptor-mediated plant immunity: from structure to cell death. Nat Rev Immunol. 2021; 21:305-318. doi: 10.1038/s41577-020-00473-z. PMID: 33293618

Schulze S, Yu L, Ehinger A, Kolb D, Saile SC, Stahl M, Franz-Wachtel M, Li L, El Kasmi F, Cevik V, Kemmerling B. The TIR-NBSLRR protein CSA1 is required for autoimmune cell death in Arabidopsis pattern recognition co-receptor bak1 and bir3 mutants. bioRxiv. 2021; doi: https://doi.org/10.1101/2021.04.11.438637.

Segretin ME, Pais M, Franceschetti M, Chaparro-Garcia A, Bos Jl, Banfield MJ, Kamoun S. Single amino acid mutations in the potato immune receptor R3a expand response to Phytophthora effectors. Mol Plant Microbe Interact. 2014; 27:624-637. doi: 10.1094/MPMI-02-14-0040-R. PMID: 24678835

Shao ZQ, Xue JY, Wu P, Zhang YM, Wu Y, Hang YY, Wang B, Chen JQ. Large-scale analyses of angiosperm nucleotide-binding site-leucine-rich repeat genes reveal three anciently diverged classes with distinct evolutionary patterns. Plant Physiol. 2016; 170:2095-109. doi: 10.1104/pp.15.01487. PMID: 26839128

Shirano Y, Kachroo P, Shah J, Klessig DF. A gain-of-function mutation in an Arabidopsis Toll Interleukin1 receptor-nucleotide binding site-leucine-rich repeat type $R$ gene triggers defense responses and results in enhanced disease resistance. Plant Cell. 2002; 14:3149-3162. doi: 10.1105/tpc.005348. PMID: 12468733

Sohn KH, Segonzac C, Rallapalli G, Sarris PF, Woo JY, Williams SJ, Newman TE, Paek KH, Kobe B, Jones JD. The nuclear immune receptor RPS4 is required for $R R S 1^{S L H 1}$-dependent constitutive defense activation in Arabidopsis thaliana. PLoS Genet. 2014; 10:e1004655. doi: 10.1371/journal.pgen.1004655. PMID: 25340333

Spassova MI, Prins TW, Folkertsma RT, Klein-Lankhorst RM, Hille J, Goldbach RW, Prins M. The tomato gene Sw5 is a member of the coiled coil, nucleotide binding, leucine-rich repeat class of plant resistance genes and confers resistance to TSWV in tobacco. Molecular Breeding. 2001; 7:151-161. doi:10.1023/A:1011363119763.

Stamatakis A. RAxML version 8: a tool for phylogenetic analysis and post-analysis of large phylogenies. Bioinformatics. 2014; 30:1312-1313. doi: 10.1093/bioinformatics/btu033. PMID: 24451623

Tamborski J, Krasileva KV. Evolution of plant NLRs: from natural history to precise modifications. Annu Rev Plant Biol. 2020; 71:355-378. doi: 10.1146/annurev-arplant-081519-035901. PMID: 32092278

Tameling WI, Baulcombe DC. Physical association of the NB-LRR resistance protein Rx with a Ran GTPase-activating protein is required for extreme resistance to Potato virus X. Plant Cell. 2007; 19:1682-1694. doi: 10.1105/tpc.107.050880. PMID: 17526750

Tian H, Wu Z, Chen S, Ao K, Huang W, Yaghmaiean H, Sun T, Xu F, Zhang Y, Wang S, Li X, Zhang Y. Activation of TIR signalling boosts pattern-triggered immunity. Nature. 2021; 598:500-503. doi: 10.1038/s41586-021-03987-1. PMID: 34544113

Tran DTN, Chung EH, Habring-Müller A, Demar M, Schwab R, Dangl JL, Weigel D, Chae E. Activation of a plant NLR complex through heteromeric association with an autoimmune risk variant of another NLR. Curr Biol. 2017; 27:1148-1160. doi: 10.1016/j.cub.2017.03.018. PMID: 28416116

Tsuchiya T, Eulgem T. Mutations in EDM2 selectively affect silencing states of transposons and induce plant developmental plasticity. Sci Rep. 2013; 3:1701. doi: 10.1038/srep01701. PMID: 23609044

Uehling J, Deveau A, Paoletti M. Do fungi have an innate immune response? An NLR-based comparison to plant and animal immune systems. PLoS Pathog. 2017; 13:e1006578. doi: 10.1371/journal.ppat.1006578. PMID: 29073287

Van de Weyer AL, Monteiro F, Furzer OJ, Nishimura MT, Cevik V, Witek K, Jones JDG, Dangl JL, Weigel D, Bemm F. A Specieswide inventory of NLR genes and alleles in Arabidopsis thaliana. Cell. 2019; 178:1260-1272.e14. doi: 10.1016/j.cell.2019.07.038. PMID: 31442410

Wan WL, Kim ST, Castel B, Charoennit N, Chae E. Genetics of autoimmunity in plants: an evolutionary genetics perspective. New Phytol. 2021; 229: 1215-1233. doi: 10.1111/nph.16947. PMID: 32970825 
bioRxiv preprint doi: https://doi.org/10.1101/2021.11.15.468391; this version posted November 15,2021 . The copyright holder for this preprint (which was not certified by peer review) is the author/funder, who has granted bioRxiv a license to display the preprint in perpetuity. It is made available under aCC-BY 4.0 International license.

Wang Y, Zhang Y, Wang Z, Zhang X, Yang S. A missense mutation in CHS1, a TIR-NB protein, induces chilling sensitivity in Arabidopsis. Plant J. 2013; 75:553-565. doi: 10.1111/tpj.12232. PMID: 23651299

Wang J, Hu M, Wang J, Qi J, Han Z, Wang G, Qi Y, Wang HW, Zhou JM, Chai J. Reconstitution and structure of a plant NLR resistosome conferring immunity. Science. 2019a; 364:eaav5870. doi: 10.1126/science.aav5870. PMID: 30948527

Wang J, Wang J, Hu M, Wu S, Qi J, Wang G, Han Z, Qi Y, Gao N, Wang HW, Zhou JM, Chai J. Ligand-triggered allosteric ADP release primes a plant NLR complex. Science. 2019b; 364:eaav5868. doi: 10.1126/science.aav5868. PMID: 30948526

Witek K, Lin X, Karki HS, Jupe F, Witek Al, Steuernagel B, Stam R, van Oosterhout C, Fairhead S, Heal R, Cocker JM, Bhanvadia $\mathrm{S}$, Barrett W, Wu CH, Adachi H, Song T, Kamoun S, Vleeshouwers VGAA, Tomlinson L, Wulff BBH, Jones JDG. A complex resistance locus in Solanum americanum recognizes a conserved Phytophthora effector. Nat Plants. 2021; 7:198-208. doi: 10.1038/s41477-021-00854-9. PMID: 33574576

Wu CH, Belhaj K, Bozkurt TO, Birk MS, Kamoun S. Helper NLR proteins NRC2a/b and NRC3 but not NRC1 are required for Ptomediated cell death and resistance in Nicotiana benthamiana. New Phytol. 2016; 209:1344-1352. doi: 10.1111/nph.13764. PMID: 26592988

Wu CH, Abd-El-Haliem A, Bozkurt TO, Belhaj K, Terauchi R, Vossen JH, Kamoun S. NLR network mediates immunity to diverse plant pathogens. Proc Natl Acad Sci U S A. 2017; 114:8113-8118. doi: 10.1073/pnas.1702041114. PMID: 28698366

Wu CH, Derevnina L, Kamoun S. Receptor networks underpin plant immunity. Science. 2018; 360:1300-1301. doi: 10.1126/science.aat2623. PMID: 29930125

Wu CH, Adachi H, De la Concepcion JC, Castells-Graells R, Nekrasov V, Kamoun S. NRC4 gene cluster is not essential for bacterial flagellin-triggered immunity. Plant Physiol. 2020; 182:455-459. doi: 10.1104/pp.19.00859. PMID: 31712307

Wu Y, Gao Y, Zhan Y, Kui H, Liu H, Yan L, Kemmerling B, Zhou JM, He K, Li J. Loss of the common immune coreceptor BAK1 leads to NLR-dependent cell death. Proc Natl Acad Sci U S A. 2020; 117:27044-27053. doi: 10.1073/pnas.1915339117. PMID: 33055218

Xu F, Zhu C, Cevik V, Johnson K, Liu Y, Sohn K, Jones JD, Holub EB, Li X. Autoimmunity conferred by chs3-2D relies on CSA1, its adjacent TNL-encoding neighbour. Sci Rep. 2015; 5:8792. doi: 10.1038/srep08792. PMID: 25740259

Yan P, Shen W, Gao X, Li X, Zhou P, Duan J. High-throughput construction of intron-containing hairpin RNA vectors for RNAi in plants. PLoS One. 2012; 7:e38186. doi: 10.1371/journal.pone.0038186. PMID: 22675447

Yang H, Shi Y, Liu J, Guo L, Zhang X, Yang S. A mutant CHS3 protein with TIR-NB-LRR-LIM domains modulates growth, cell death and freezing tolerance in a temperature-dependent manner in Arabidopsis. Plant J. 2010; 63:283-296. doi: 10.1111/j.1365-313X.2010.04241.x. PMID: 20444230

Yu A, Lepère G, Jay F, Wang J, Bapaume L, Wang Y, Abraham AL, Penterman J, Fischer RL, Voinnet O, Navarro L. Dynamics and biological relevance of DNA demethylation in Arabidopsis antibacterial defense. Proc Natl Acad Sci U S A. 2013; 110:2389-2394. doi: 10.1073/pnas.1211757110. PMID: 23335630

Zhang Y, Goritschnig S, Dong X, Li X. A gain-of-function mutation in a plant disease resistance gene leads to constitutive activation of downstream signal transduction pathways in suppressor of npr1-1, constitutive 1. Plant Cell. 2003; 15:26362646. doi: 10.1105/tpc.015842. PMID: 14576290

Zhang Z, Wu Y, Gao M, Zhang J, Kong Q, Liu Y, Ba H, Zhou J, Zhang Y. Disruption of PAMP-induced MAP kinase cascade by a Pseudomonas syringae effector activates plant immunity mediated by the NB-LRR protein SUMM2. Cell Host Microbe. 2012; 11:253-63. doi: 10.1016/j.chom.2012.01.015. PMID: 22423965

Zhang Y, Wang Y, Liu J, Ding Y, Wang S, Zhang X, Liu Y, Yang S. Temperature-dependent autoimmunity mediated by chs1 requires its neighboring TNL gene SOC3. New Phytol. 2017; 213:1330-1345. doi: 10.1111/nph.14216. PMID: 27699788 
bioRxiv preprint doi: https://doi.org/10.1101/2021.11.15.468391; this version posted November 15, 2021. The copyright holder for this preprint (which was not certified by peer review) is the author/funder, who has granted bioRxiv a license to display the preprint in perpetuity. It is made available under aCC-BY 4.0 International license.

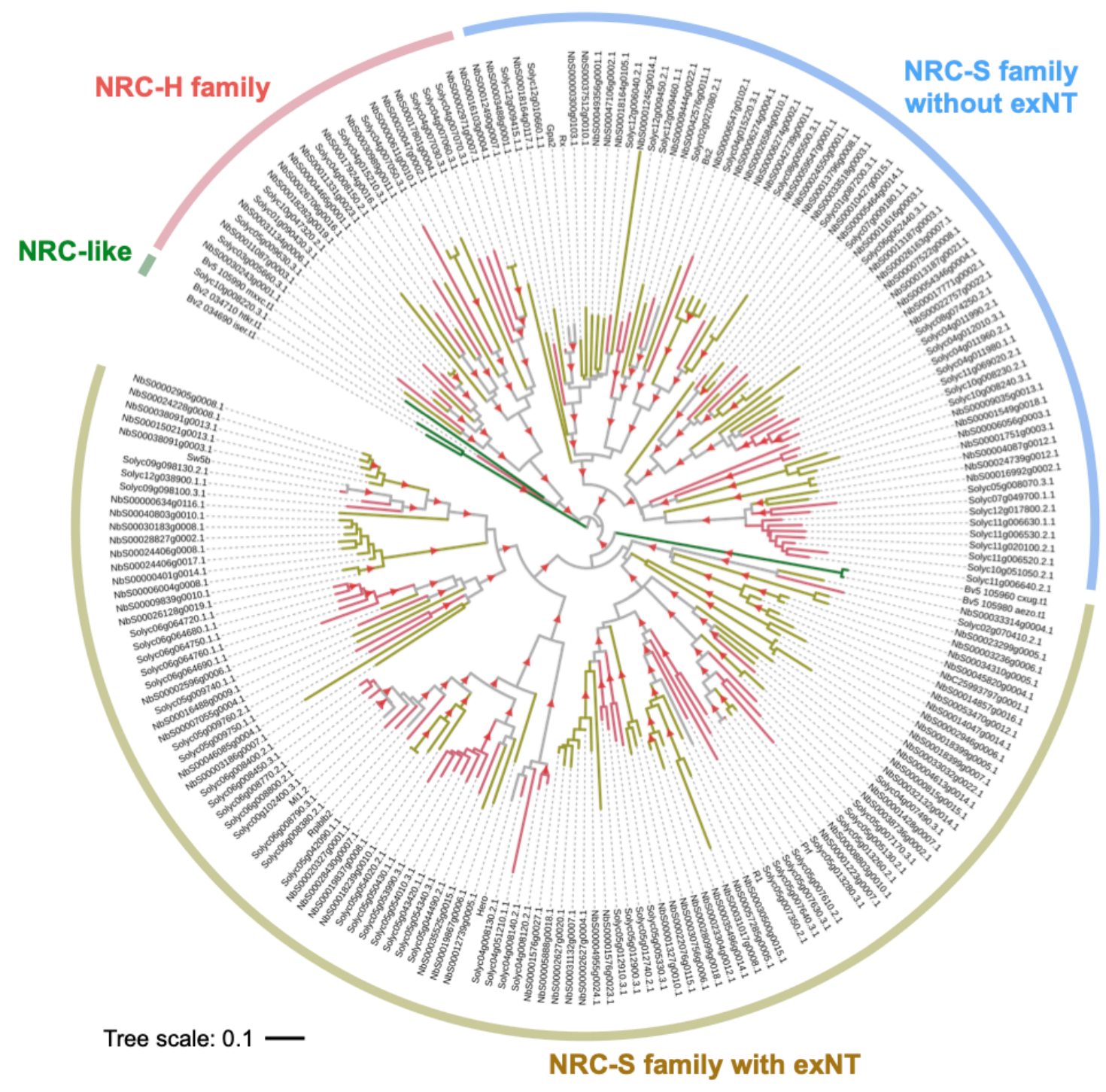

Fig. S1. Phylogenetic tree of NRC superclade. NRC-sensor (NRC-S) and NRC-helper (NRC-H) proteins identified in Adachi et al. (2019b) were used for the MAFFT multiple alignment and phylogenetic analyses. The phylogenetic tree was constructed with the NB-ARC domain sequences in MEGA7 by the neighbour-joining method. Each leaf is labelled with different colour ranges indicating plant species, N. benthamiana (NbS-), tomato (Solyc-) and sugar beet (Bv-). The NRC-S clade is divided into NLRs that lack an extended N-terminal domain (exNT) prior to their CC domain and those that carry an exNT. Red arrow heads indicate bootstrap support $>0.7$. The scale bars indicate the evolutionary distance in amino acid substitution per site. 
bioRxiv preprint doi: https://doi.org/10.1101/2021.11.15.468391; this version posted November 15, 2021. The copyright holder for this

preprint (which was not certified by peer review) is the author/funder, who has granted bioRxiv a license to display the preprint in perpetuity. It is made available under aCC-BY 4.0 International license.

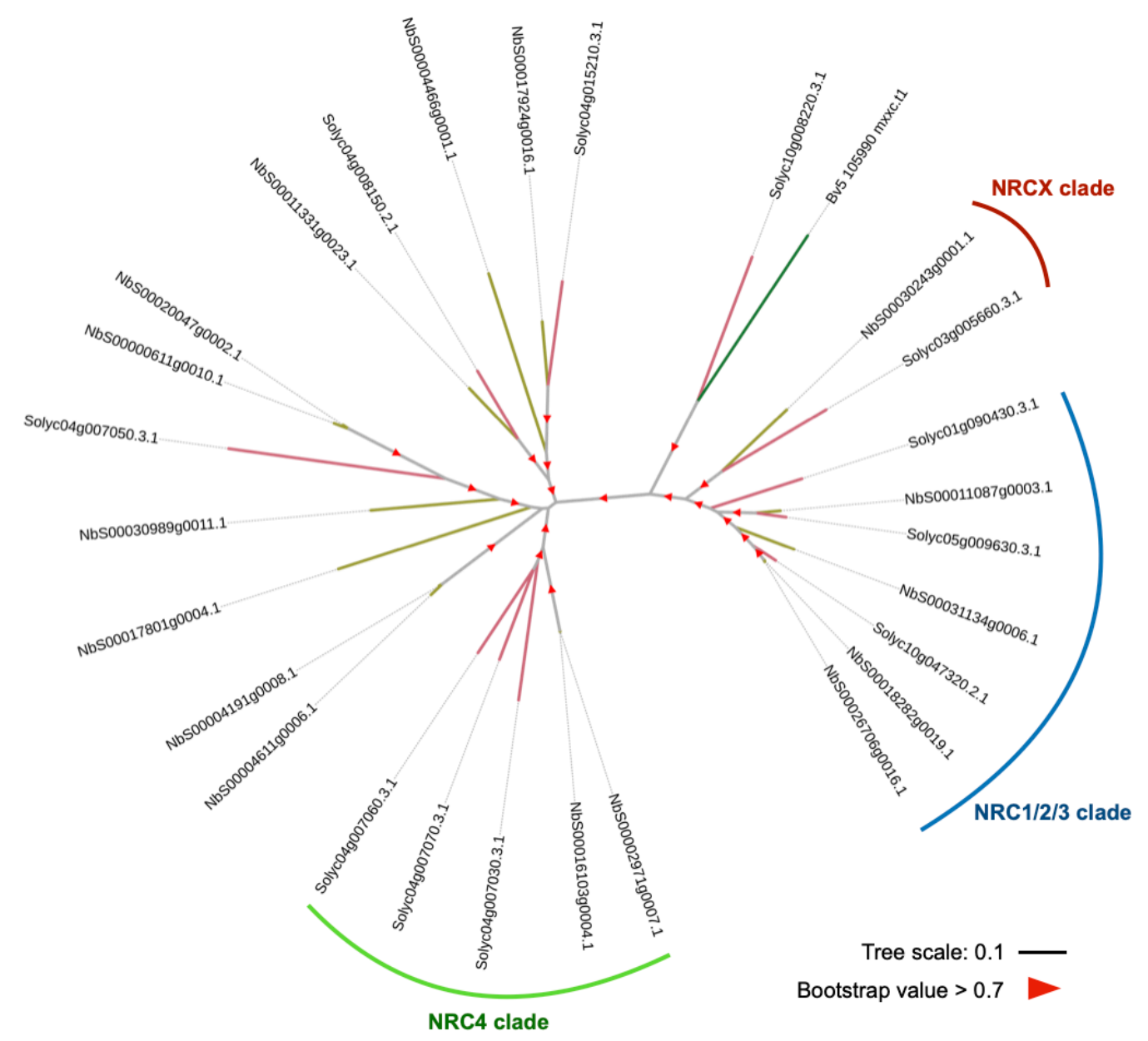

Fig. S2. NRC-H subclade shown in Figure 2B. 
bioRxiv preprint doi: https://doi.org/10.1101/2021.11.15.468391; this version posted November $15,2021$. The copyright holder for this

preprint (which was not certified by peer review) is the author/funder, who has granted bioRxiv a license to display the preprint in perpetuity. It is made available under aCC-BY 4.0 International license.

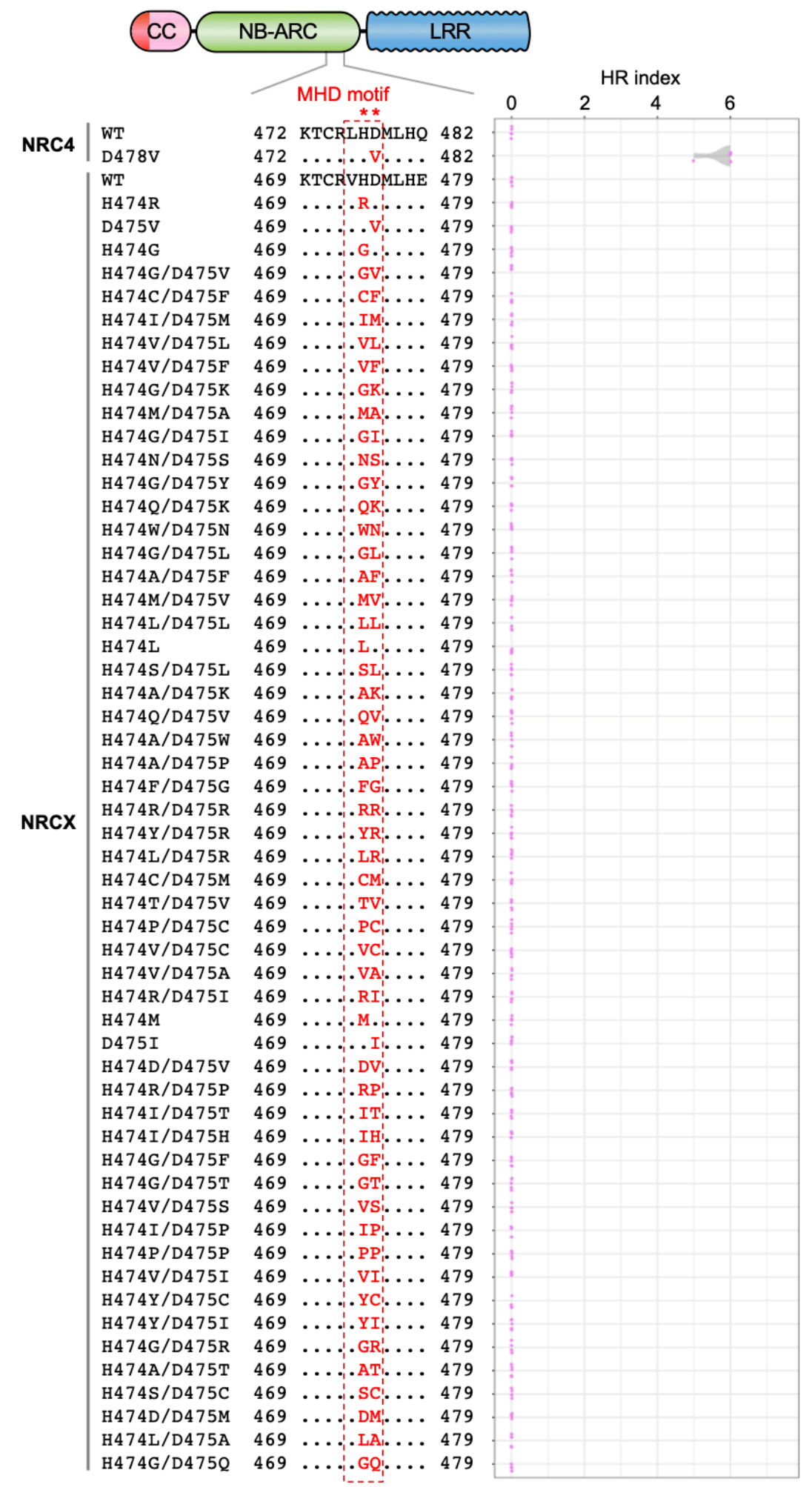

Fig. S3. 55 independent NRCX MHD mutants do not cause autoactive cell death in N. benthamiana. Cell death phenotypes were scored at an HR index at 5 days after agroinfiltration to express NRC4 ${ }^{\mathrm{WT}}$, NRCX ${ }^{\mathrm{WT}}$ and the MHD mutants in $N$. benthamiana leaves. Quantification data are from 5 independent biological replicates. 
A

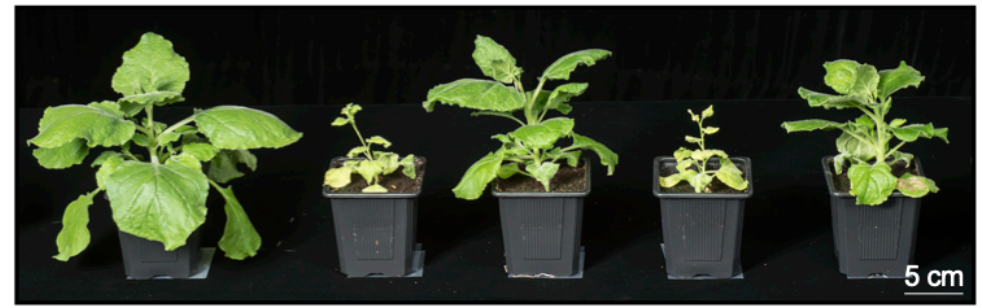

TRV:

EV

NRCX

NRC2/3/X NRC4/X NRC2/3/4/X

B
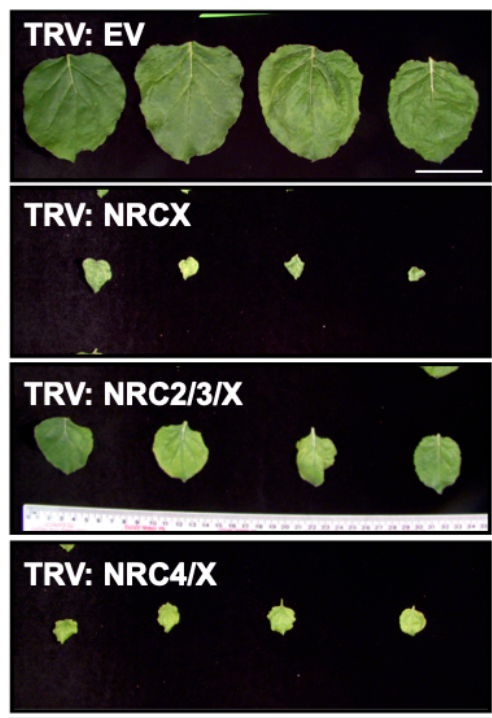

TRV: NRC2/3/4/X

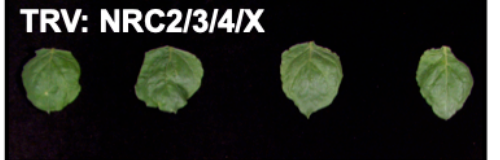

C

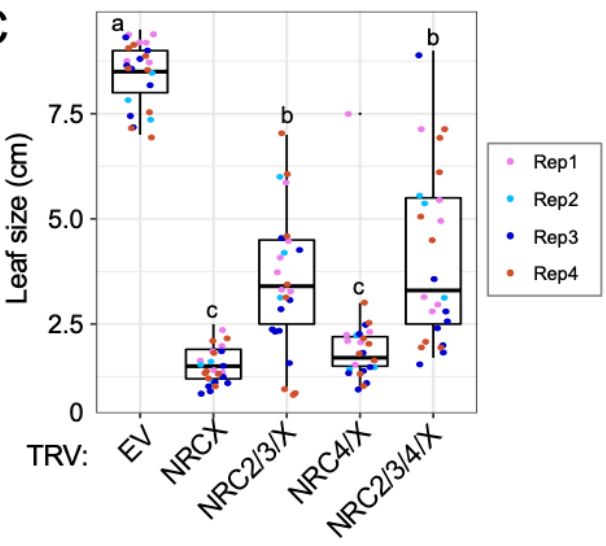

D

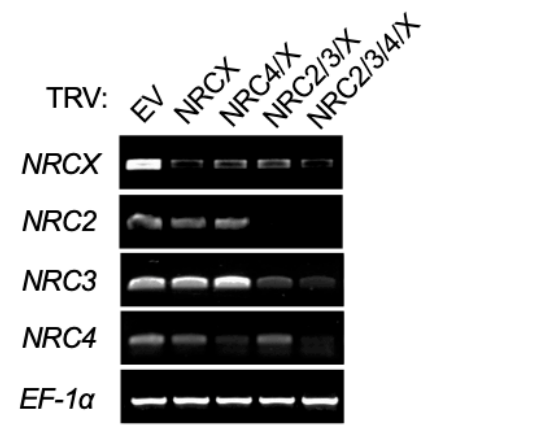

Fig. S4. Co-silencing of NRC2 and NRC3 partially suppresses TRV:NRCX dwarf phenotype in N. benthamiana. (A) The morphology of 6-week-old NRCX-, NRC2/3/X-, NRC4/X-and NRC2/3/4/X-silenced $N$. benthamiana plants. 2-week-old $N$. benthamiana plants were infiltrated with Agrobacterium strains carrying VIGS constructs, and photographs were taken 4 weeks after the agroinfiltration. TRV empty vector (TRV:EV) was used as a negative control. (B, C) Quantification of the leaf size. One leaf per each plant was harvested from the same position (the 5 th leaf from cotyledons) and was used for measuring the leaf diameter. Statistical differences among the samples were analyzed with Tukey's HSD test $(p<0.01)$. Scale bars $=5 \mathrm{~cm}$. (D) Specific gene silencing of $N R C X$ or multiple NRC genes in TRV:NRC-infected plants. Leaf samples were collected for RNA extraction at 3 weeks after agroinfiltration expressing VIGS constructs. The expression of NRCX and other NRC genes were analyzed in semiquantitative RT-PCR using specific primer sets. Elongation factor $1 \alpha(E F-1 \alpha)$ was used as an internal control. Scale bars $=5 \mathrm{~cm}$. 


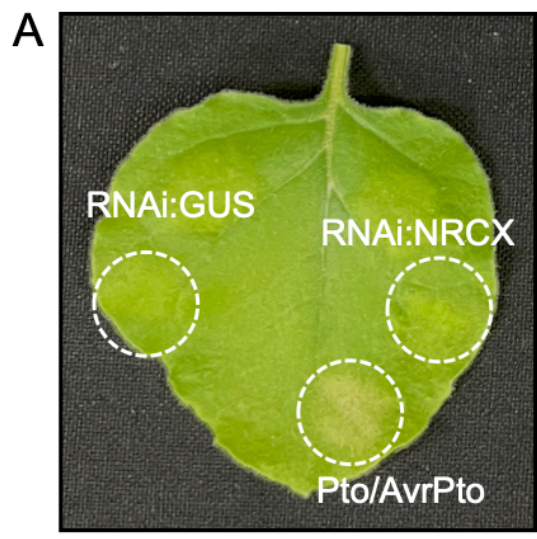

B

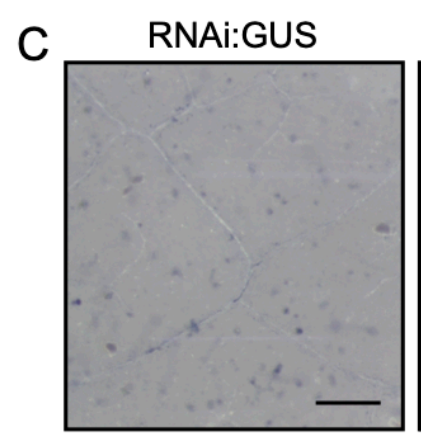

RNAi:NRCX

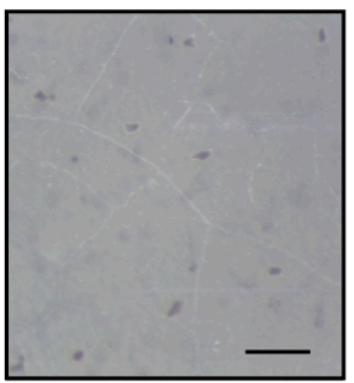

RNAi:GUS RNAi:NRCX<smiles>C1CCCCC1</smiles><smiles>c1ccccc1</smiles>

Pto/AvrPto

Pto/AvrPto

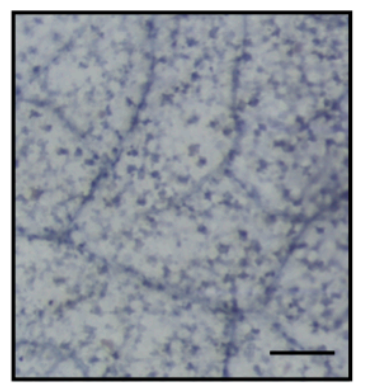

Fig. S5. RNA interference of $N R C X$ does not cause cell death in $\mathbf{N}$. benthamiana leaves (A) Macroscopic cell death phenotype after expressing RNAi:GUS, RNAi:NRCX or Pto/AvrPto by agroinfiltration. Photograph was taken at 5 days after the agroinfiltration. (B) Cell death was detected by trypan blue staining at 5 days after the agroinfiltration. (C) Microscopic cell death phenotype. Dead cells were stained by trypan blue. Images describe representative data of 8 replicates from 2 independent experiments. Scale bars are $300 \mu \mathrm{m}$. 

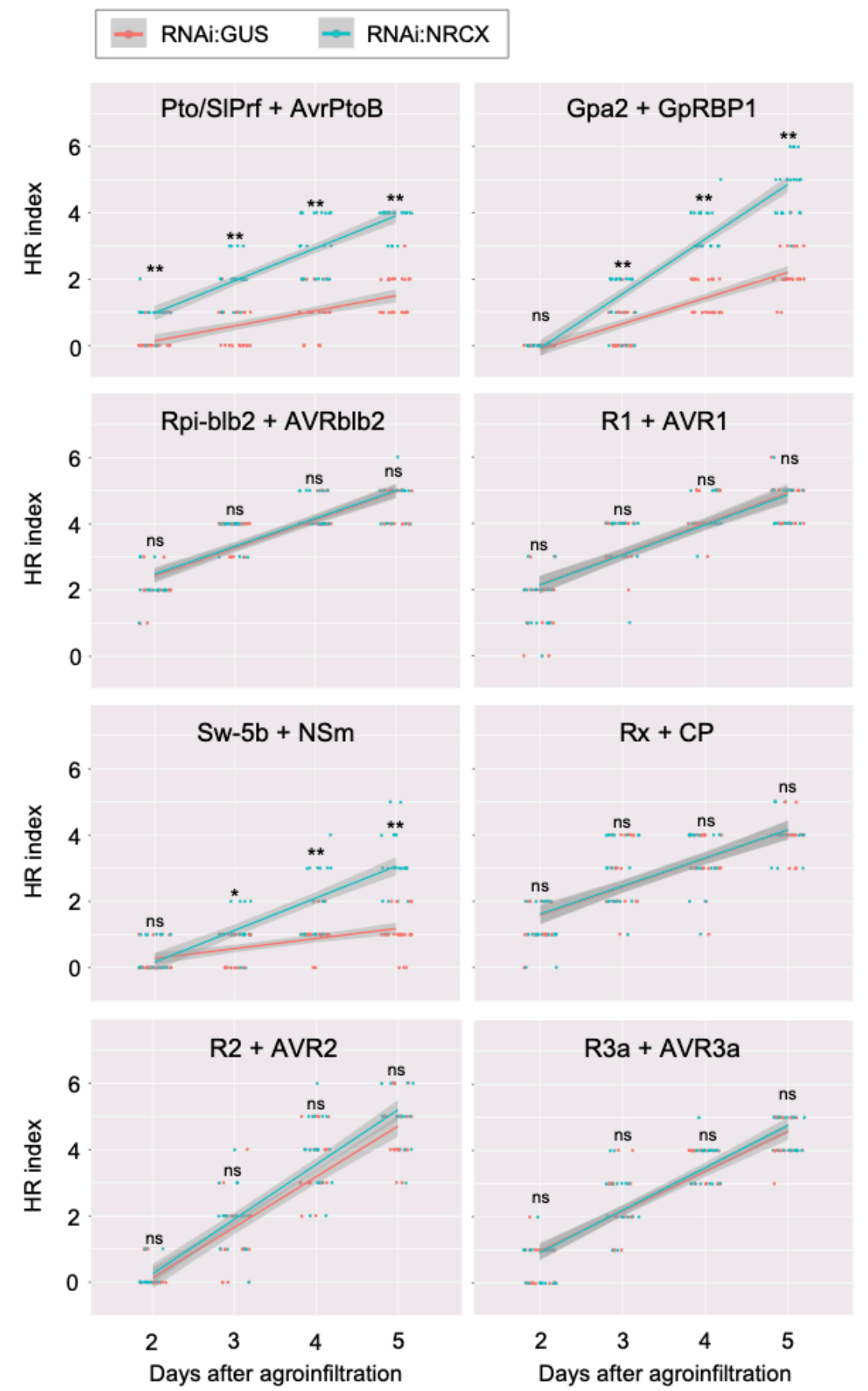

Fig. S6. Time-lapse quantification of NRC-S/AVR-triggered hypersensitive cell death in NRCX silenced leaves. Cell death intensity was scored at 2-5 days after the agroinfiltration as described in Fig 6 . The HR index plots are based on three independent experiments. Asterisks indicate statistically significant differences with $t$ test $\left({ }^{*} p<0.05\right.$ and $\left.{ }^{* *} p<0.01\right)$. Pink and blue line plots indicate mean values of RNAi:GUS and RNAi:NRCX samples at each time point. 


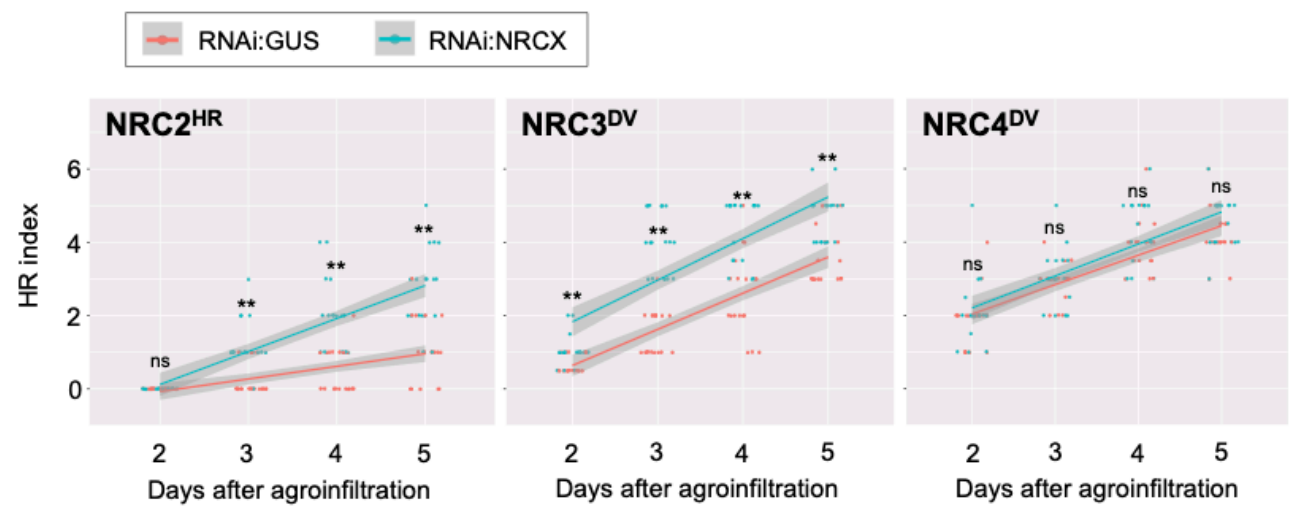

Fig. S7. Time-lapse quantification of NRC-H autoactive cell death in NRCX silenced leaves. Cell death intensity was scored at 2-5 days after the agroinfiltration as described in Fig 6. The HR index plots are based on three independent experiments. Asterisks indicate statistically significant differences with $t$ test $\left({ }^{* *} p<0.01\right)$. Pink and blue line plots indicate mean values of RNAi:GUS and RNAi:NRCX samples at each time point. 

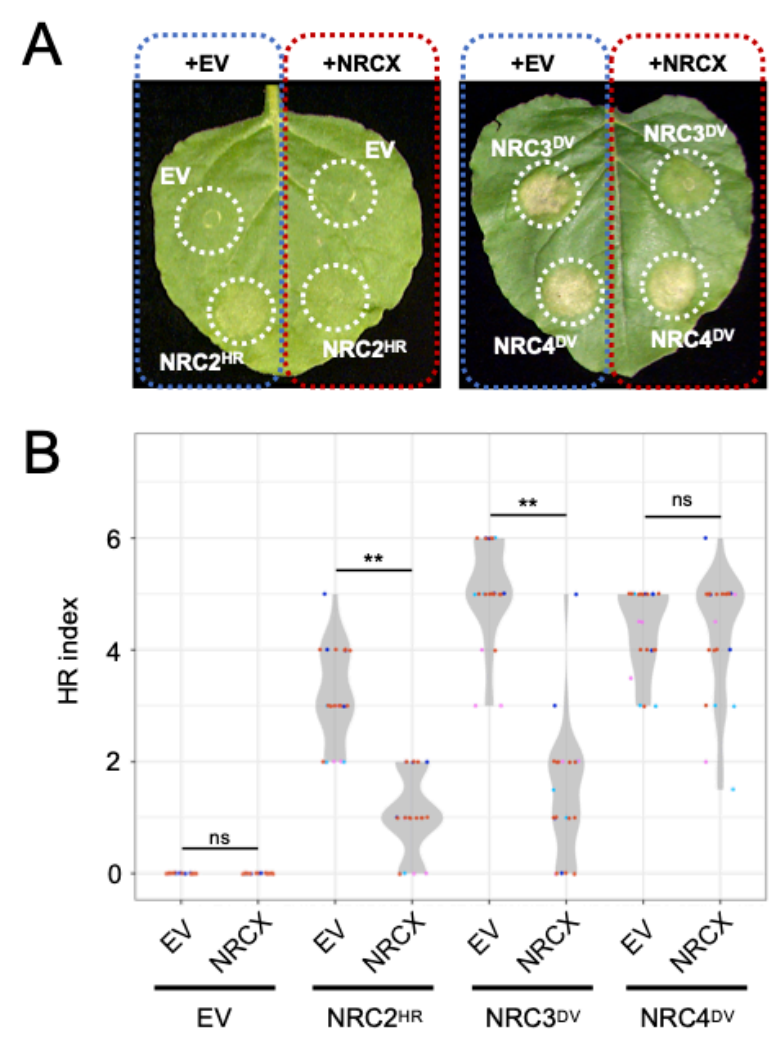

Fig. S8. Overexpression of wild-type NRCX compromises autoactive cell death of NRC2 and NRC3, but not NRC4. (A) Photo of representative N. benthamiana leaves showing autoactive cell death after co-expression of empty vector (EV; control) and wild-type $\mathrm{NRCX}$ with $\mathrm{NRC} 2^{\mathrm{HR}}, \mathrm{NRC} 3^{\mathrm{DV}}$ and $\mathrm{NRC} 4^{\mathrm{DV}}$. Photographs were taken at 5 days after agroinfiltration. (B) Violin plots showing cell death intensity scored as an HR index at 5 days after the agroinfiltration. The HR index plots are based on four independent experiments. Asterisks indicate statistically significant differences with $t$ test $(* * p<0.01)$. 


\section{Supplemental data}

Table S1. Transcriptome profiles of Nicotiana benthamiana NLR genes.

Table S2. Expression ratios of NRC2, NRC3 and NRC4 compared to NRCX.

Table S3. Primers used in this study.

Table S4. List of NLR and corresponding AVR effector used in cell death assays.

File S1. Amino acid sequences of full-length CC-NLRs used for phylogenetic analysis in Figure $2 \mathrm{~A}$.

File S2. Amino acid sequences for CC-NLR phylogenetic tree in Figure 2A.

File S3. CC-NLR phylogenetic tree file in Figure 2A. 